\title{
Comprehensive Survey of IoT, Machine Learning, and Blockchain for Health Care Applications: A Topical Assessment for Pandemic Preparedness, Challenges, and Solutions
}

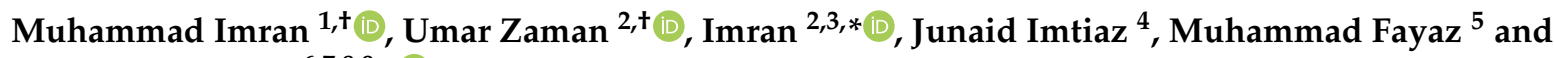 \\ Jeonghwan Gwak 6,7,8,9,*(D)
}

check for updates

Citation: Imran, M.; Zaman, U.; Imran; Imtiaz, J.; Fayaz, M.; Gwak, J. Comprehensive Survey of IoT, Machine Learning, and Blockchain for Health Care Applications: A Topical Assessment for Pandemic Preparedness, Challenges, and Solutions. Electronics 2021, 10, 2501 https://doi.org/10.3390/ electronics10202501

\section{Academic Editors: Ismaeel Al}

Ridhawi, Safa Otoum, Ali Karime and Nadra Guizani

Received: 4 September 2021

Accepted: 11 October 2021

Published: 14 October 2021

Publisher's Note: MDPI stays neutral with regard to jurisdictional claims in published maps and institutional affiliations.

Copyright: (c) 2021 by the authors. Licensee MDPI, Basel, Switzerland. This article is an open access article distributed under the terms and conditions of the Creative Commons Attribution (CC BY) license (https:// creativecommons.org/licenses/by/ $4.0 /)$.
1 Department of Computer Science, Bahria University, Islamabad 46000, Pakistan; ikhan9985@gmail.com 2 AIPSCom Convergence Lab, Islamabad 46000, Pakistan; umarzaman2010@gmail.com

3 Department of Computer Engineering, Jeju National University, Jeju 63243, Korea

4 Department of Electrical Engineering, Bahria University, Islamabad 46000, Pakistan; JunaidImtiaz.buic@bahria.edu.pk

5 Department of Computer Science, University of Central Asia, 310 Lenin Street, Naryn 722918, Kyrgyzstan; muhammad.fayaz@ucentralasia.org

6 Department of Software, Korea National University of Transportation, Chungju 27469, Korea

7 Department of Biomedical Engineering, Korea National University of Transportation, Chungju 27469, Korea

8 Department of AI Robotics Engineering, Korea National University of Transportation, Chungju 27469, Korea

9 Department of IT \& Energy Convergence (BK21 FOUR), Korea National University of Transportation, Chungju 27469, Korea

* Correspondence: imranjofficial@jejunu.ac.kr (I.); jgwak@ut.ac.kr (J.G.)

$\dagger$ These authors contributed equally to this work.

Abstract: Internet of Things (IoT) communication technologies have brought immense revolutions in various domains, especially in health monitoring systems. Machine learning techniques coupled with advanced artificial intelligence techniques detect patterns associated with diseases and health conditions. Presently, the scientific community is focused on enhancing IoT-enabled applications by integrating blockchain technology with machine learning models to benefit medical report management, drug traceability, tracking infectious diseases, etc. To date, contemporary state-of-the-art techniques have presented various efforts on the adaptability of blockchain and machine learning in IoT applications; however, there exist various essential aspects that must also be incorporated to achieve more robust performance. This study presents a comprehensive survey of emerging IoT technologies, machine learning, and blockchain for healthcare applications. The reviewed articles comprise a plethora of research articles published in the web of science. The analysis is focused on research articles related to keywords such as 'machine learning', blockchain, 'Internet of Things or IoT', and keywords conjoined with 'healthcare' and 'health application' in six famous publisher databases, namely IEEEXplore, Nature, ScienceDirect, MDPI, SpringerLink, and Google Scholar. We selected and reviewed 263 articles in total. The topical survey of the contemporary IoT-based models is presented in healthcare domains in three steps. Firstly, a detailed analysis of healthcare applications of IoT, blockchain, and machine learning demonstrates the importance of the discussed fields. Secondly, the adaptation mechanism of machine learning and blockchain in IoT for healthcare applications are discussed to delineate the scope of the mentioned techniques in IoT domains. Finally, the challenges and issues of healthcare applications based on machine learning, blockchain, and IoT are discussed. The presented future directions in this domain can significantly help the scholarly community determine research gaps to address.

Keywords: IoT; machine learning; healthcare; pandemic; blockchain; convergence; health monitoring

\section{Introduction}

Internet of Things (IoT) integrates large numbers of physical devices through the Internet to collect, share, and assess a vast amount of data [1]. Internet of Things (IoT) 
communication technologies have brought immense revolutions in various domains, especially, IoT has become elementary for the second phase of the digital revolution [2,3]. Cisco statistical analysis remarked in a study that 50 billion devices could be integrated into a single network using the Internet [4]. The integration of a large number of devices leads to scalability and data management problems. The contemporary management systems usually become old-fashioned due to the advancement and latest trends and technologies. Orchestration is one of the latest automated approaches to tackle management and scalability issues [5]. Orchestration is considered as the most cost-effective and innovative way to manage the significant number of integrated things using IoT technology [6-8]. Wireless sensor networks (WSNs), machine-to-machine (M2M), and cyber-physical systems (CPS) are the key elements in IoT $[9,10]$. These networks are processed and communicated using standard IP protocol with security concerns, which requires the safety of the whole network against security attacks. Otherwise, these cyber attacks can harm IoT services, data security, data privacy, and data integrity of the entire system [11,12].

Due to the incredible economic prospect in IoT, IT organizations and academic institutes participate in the research and advancement in IoT technologies to develop sustainable solutions. They have introduced many free and commercial plans over the last few decades; however, due to the lack of adaptability among IoT application development platforms, these technologies use many data formats, boosting the critical issue of heterogeneity; therefore, the requirement for better network management solutions to tackle the extensive amount of data generated by this integrated system arises gradually. The existing data storage and central processing model is unsuitable; hence, edge-computing solutions play an essential role in analyzing data to refine these utilities in IoT technology. Big data solutions in IoT are a new paradigm that introduces practical applications based on the enormous data generated from extensive IoT devices. Many studies have been proposed to handle various IoT issues and features such as IoT challenges, opportunities, and applications $[13,14]$. In IoT technologies, security and privacy are the leading research-oriented challenging problems. Other such challenges include IoT and cloud integration [15], IoT standardization [16], IoT scalable architecture, and IoT security [17-20]. Further, earlier literature on IoT did not consider all the issues in detail, such as dealing with Quality of Service (QoS), internet applications, and security challenges.

Figure 1 shows applications of machine learning, blockchain, and IoT for the healthcare domain. Artificial intelligence and IoT have been consolidated to form a new specification named Artificial Intelligence of Things (AIoT). The primary purpose of AIoT is to improve human-machine interactions, enhance data management, and carry out data analysis. Researchers communicate and collect data using IoT devices, and collected data are stored in a centralized database. Then, anomaly detection and automatic pattern recognition in the collected data can be performed with machine learning models. Machine learning technologies predict more accurately and faster than traditional business intelligence (BI) tools [21].

Machine learning algorithms are trained on historical network data to obtain better models that analyze data and provision network services efficiently [22]. In recent studies, machine learning offers clear instructions to implement machine learning algorithms to networking. Thus, machine learning enhances the security, efficiency, and performance of network applications [23]. The innovations and discovery of new data processing, data analysis, and predictive analysis enable the development of intelligent applications [24-26]. Many smart architectures are proposed and based on the Internet of Things, blockchain, machine learning, and their integrated mechanisms [26-28].

Blockchain is considered a public ledger and a type of database distinct from traditional databases such as relational databases [29,30]. Alternatively, blockchain saves data in blocks and then chains them together based on digital signatures in a distributed network. As new data are collected, it is passed through a new block. Blockchain key attributes include persistency, anonymity, auditability, and decentralization. Some examples of the usage of blockchain in the financial market are digital assets, remittance, and online pay- 
ment systems [31]. Recently, blockchain has been applied to emerging technologies such as IoT-based public and security services. In addition, organizations use blockchain for high reliability and security to attract customers. Furthermore, blockchain can ignore the single point of failure issue since it is a distributed environment.

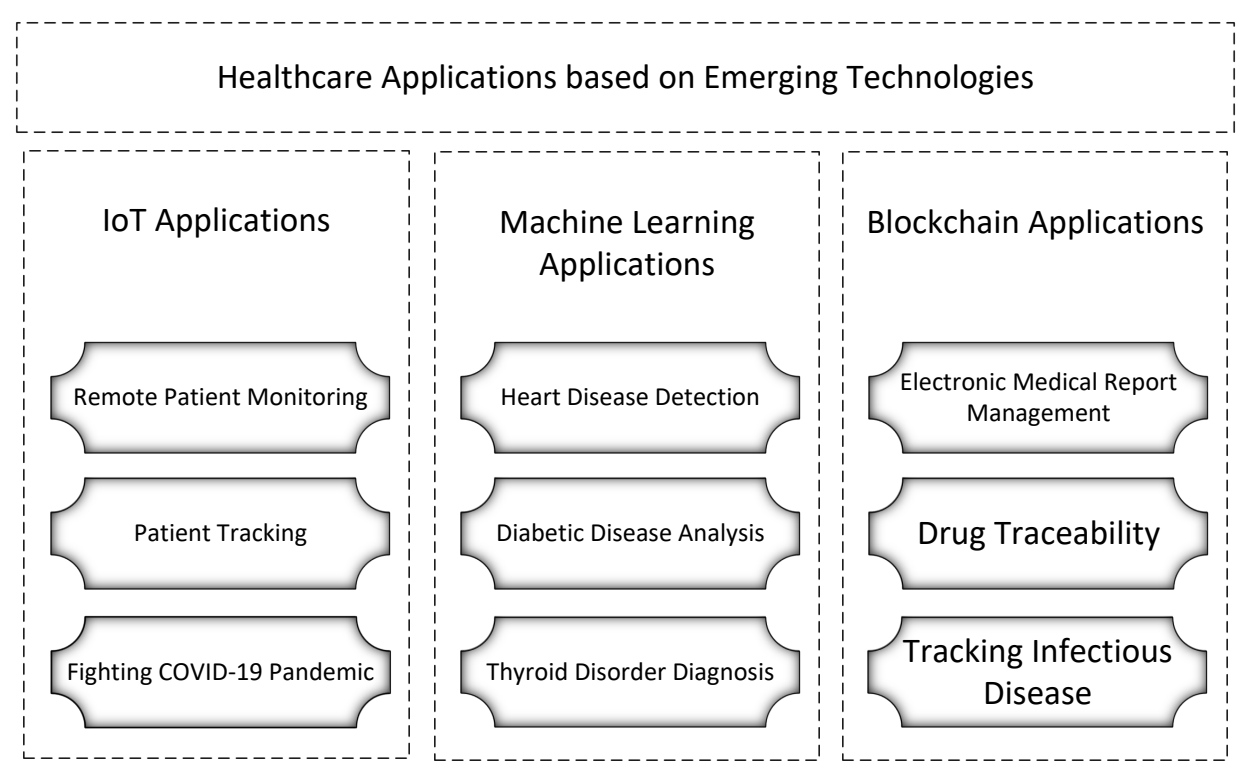

Figure 1. Healthcare applications based on IoT, machine learning, and blockchain.

Currently, there is accelerated development in healthcare because of the progression of advanced technologies such as IoT, blockchain, and machine learning. To date, contemporary state-of-the-art techniques have presented various efforts on the adaptability of blockchain and machine learning in IoT applications [32,33]. These technologies benefit healthcare systems by predicting diseases, drug tracing, patient tracking, and combating deadlier pandemics such as COVID-19. In addition, IoT and network applications security has been addressed using mechanisms based on blockchain technology [34]. Furthermore, machine learning models based on the huge amount of data collected from medical sensors and devices are used to predict and classify different healthcare diseases [35]. Machine learning techniques coupled with advanced artificial intelligence techniques detect patterns associated with diseases and health conditions. For instance, IoT-enabled applications integrate blockchain technologies with machine learning models to benefit medical report management, drug traceability, tracking infectious diseases, etc.

This study presents a comprehensive survey of emerging IoT technologies, machine learning, and blockchain for healthcare applications. These health care applications are derived from the recent web of science indexed literature. Lastly, we briefly discuss IoT, machine learning, and blockchain-based approaches that can be used to defeat the COVID19 outbreak. A topical survey of the contemporary IoT-based models is presented in healthcare domains as follows:

- A detailed analysis of healthcare applications of IoT, blockchain, and machine learning demonstrates the importance of the discussed fields.

- The adaptation mechanism of machine learning and blockchain in IoT for healthcare applications are discussed to delineate the scope of the mentioned techniques in IoT domains.

- The challenges and issues of healthcare applications based on machine learning, blockchain, and IoT are discussed.

- COVID-19 applications based on blockchain, machine learning, and IoT are discussed as use cases for future pandemic preparedness. 
The presented future directions in this domain can significantly help the scholarly community pick the accurate research gap to address; however, various essential aspects must also be incorporated to achieve more robust performance.

The rest of the paper is divided as follows: Section 2 explains the methodology of the review study. Section 3 describes the background of IoT, machine learning, and blockchain. Section 4 presents the emerging technologies based on IoT, machine learning, and blockchain for healthcare applications. In Section 5, we briefly discuss the COVID19 outbreak and research contributions. Section 6 presents the convergence of machine learning, blockchain, and IoT for health care applications and future research directions. Section 7 presents the conclusion and future research directions.

\section{Research Methodology and Results}

In this section, the methodology of the topical survey of the contemporary IoT-based models is presented in healthcare domains based on blockchain, IoT, and machine learning. In addition, the research objectives, questions, and research selection conditions of this study are discussed. Finally, this survey article investigates current academic works proposed in machine learning and blockchain for secure IoT systems. First, background to machine learning, blockchain, and IoT will be presented. Second, healthcare applications based on these emerging technologies will be presented. Third, the COVID-19 case study based on these emerging technologies will be presented. Moreover, we will discuss the convergence and adaptability of these technologies with their challenges and solutions. Figure 2 shows the research methodology of papers collection and selection for the topical survey of healthcare applications based on machine learning, blockchain, and IoT.

The primary purpose of this review study is focused on the latest research papers and upcoming trends in blockchain, machine learning, and IoT applications to combat pandemic diseases. Table 1 shows the research keywords criteria for selection of research papers. These keywords are based on IoT, blockchain, machine learning, COVID-19, and adoption of blockchain in IoT. Furthermore, keywords such as artificial intelligence and machine learning in IoT were used to filter the search criteria of articles and review papers. Table 2 presents research questions for the literature selection and review.

Table 1. Criteria and the searched keywords.

\begin{tabular}{ll}
\hline Key & Criteria \\
\hline & ("blockchain" or "Blockchain") AND (IoT OR “Internet of Things") AND \\
(COVID-19 OR “coronavirus") AND ("machine learning") AND (applications \\
of blockchain OR “IoT challenges" OR IoT solutions using blockchain) AND \\
(AIOT OR “Artificial intelligence-enabled Internet of Things") \\
Limiters & Article date between 2015 and 2021. \\
Expanders & Without the word "healthcare". \\
Search keyword & Search keyword appear anywhere in the research paper. \\
\hline
\end{tabular}

Table 2. Research questions for the literature review.

\begin{tabular}{lll}
\hline S.No & \multicolumn{1}{c}{ Question } & \multicolumn{1}{c}{ Description } \\
\hline 1 & $\begin{array}{l}\text { What is blockchain, and different concepts in } \\
\text { blockchain-related to healthcare? }\end{array}$ & $\begin{array}{l}\text { Examine review role to blockchain and finding better techniques } \\
\text { in healthcare based on blockchain. }\end{array}$ \\
\hline 2 & $\begin{array}{l}\text { What is machine learning, and different concepts of } \\
\text { machine learning related to healthcare? }\end{array}$ & $\begin{array}{l}\text { Examine review role to machine learning and finding better tech- } \\
\text { niques in healthcare based on machine learning. }\end{array}$ \\
\hline 3 & $\begin{array}{l}\text { What is the Internet of Things (IoT), and different } \\
\text { concepts in healthcare-related to IoT? }\end{array}$ & $\begin{array}{l}\text { Examine review role to IoT and finding better techniques in health- } \\
\text { care based on IoT technology. }\end{array}$ \\
\hline & $\begin{array}{l}\text { What is COVID-19 disease, and how to tackle } \\
\text { COVID-19 challenges using the latest technologies? }\end{array}$ & $\begin{array}{l}\text { To investigate different IoT, machine learning, and blockchain } \\
\text { concepts associated with healthcare, issues, and solutions used to } \\
\text { overcome these challenges. }\end{array}$ \\
\hline
\end{tabular}


Table 2. Cont.

\begin{tabular}{lll}
\hline S.No & \multicolumn{1}{c}{ Question } & \multicolumn{1}{c}{ Description } \\
\hline 5 & $\begin{array}{l}\text { Which machine learning algorithms have been used in } \\
\text { healthcare applications? }\end{array}$ & $\begin{array}{l}\text { To pick out the most used and suggested machine learning techniques } \\
\text { applied with healthcare-based methods. }\end{array}$ \\
\hline 6 & $\begin{array}{l}\text { Which blockchain techniques have been used in healthcare } \\
\text { applications? }\end{array}$ & $\begin{array}{l}\text { To identify the most utilized and suggested blockchain applied with } \\
\text { healthcare-based methods. }\end{array}$ \\
\hline 7 & $\begin{array}{l}\text { Which IoT technologies have been used in healthcare ap- } \\
\text { plications? }\end{array}$ & $\begin{array}{l}\text { To recognize the most used and recommended IoT technologies applied } \\
\text { with healthcare-based methods. }\end{array}$ \\
\hline 8 & $\begin{array}{l}\text { How IoT, machine learning, and blockchain technologies } \\
\text { can tackle COVID-19 challenges? }\end{array}$ & $\begin{array}{l}\text { To megitate pandemic diseases such as COVID-19 disease, these tech- } \\
\text { nologies are being utilized with medical systems. }\end{array}$ \\
\hline 9 & $\begin{array}{l}\text { How to overcome the challenges of the adoption of } \\
\text { blockchain in IoT? }\end{array}$ & $\begin{array}{l}\text { Some characteristics are being upgraded using the latest research studies } \\
\text { to overcome issues while adopting blockchain in IoT. }\end{array}$ \\
\hline 10 & $\begin{array}{l}\text { How artificial intelligence-enabled IoT systems can } \\
\text { improve interactions between machine-to-human and } \\
\text { machine-to-machine? }\end{array}$ & $\begin{array}{l}\text { Analysis and comparison of AIOT applications. Analyzing if AIOT based } \\
\text { applications significantly enhance IoT solutions. }\end{array}$ \\
\hline
\end{tabular}

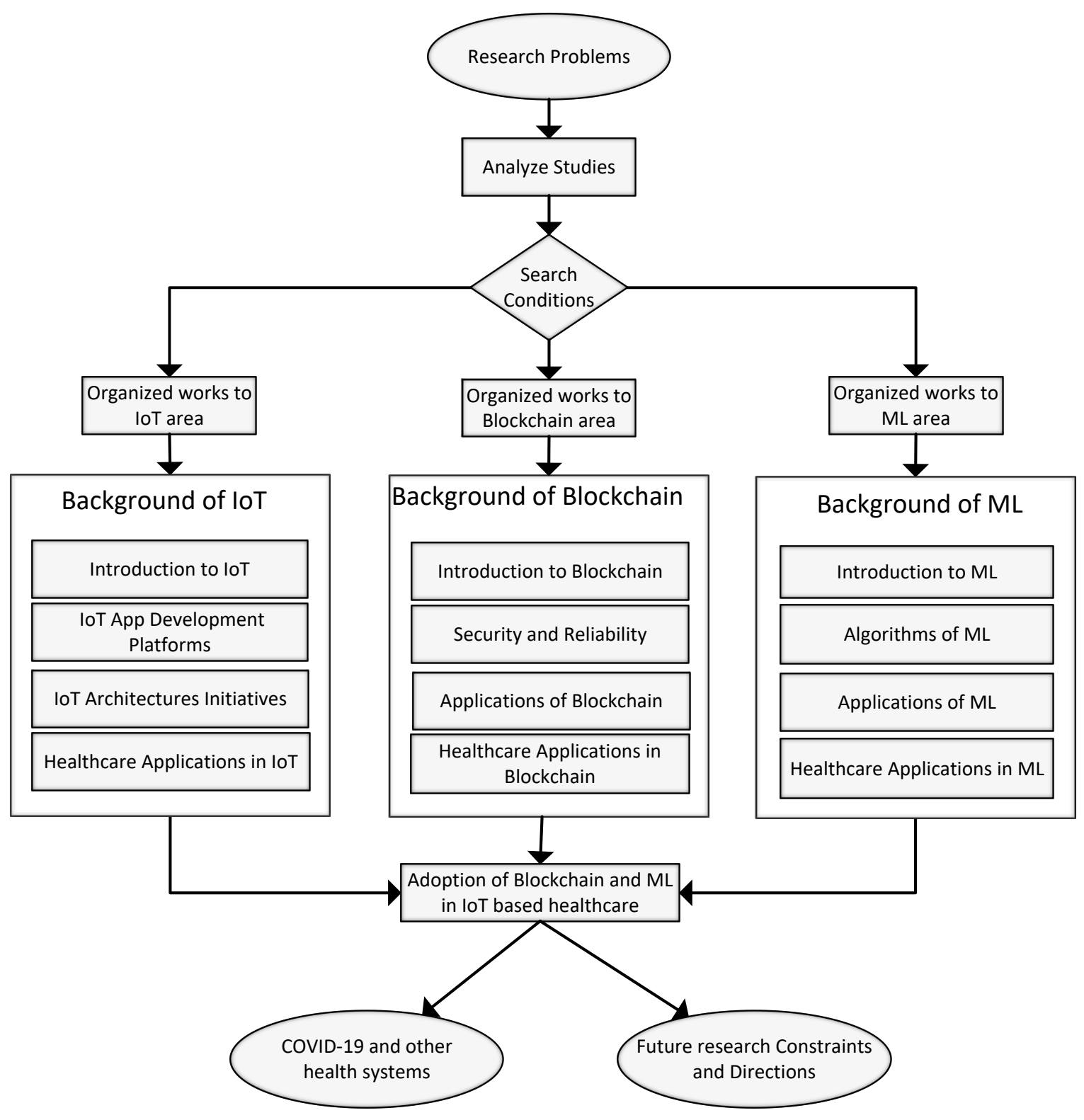

Figure 2. Methodology for Topical Survey of IoT, Blockchain and Mchine learning for Healthcare Applications. 
A total of 263 research papers and articles were selected and cited in this topical review paper. The selection was made based on different panoramas such as search engines, sources, years of publications, to name a few. We consider the recent literature to be the basis for developing a research model that heads in the right direction. This topical review paper is based on a variety of articles based on the last six years. Figure 3 illustrates the number of publications per year that have been cited in this paper.

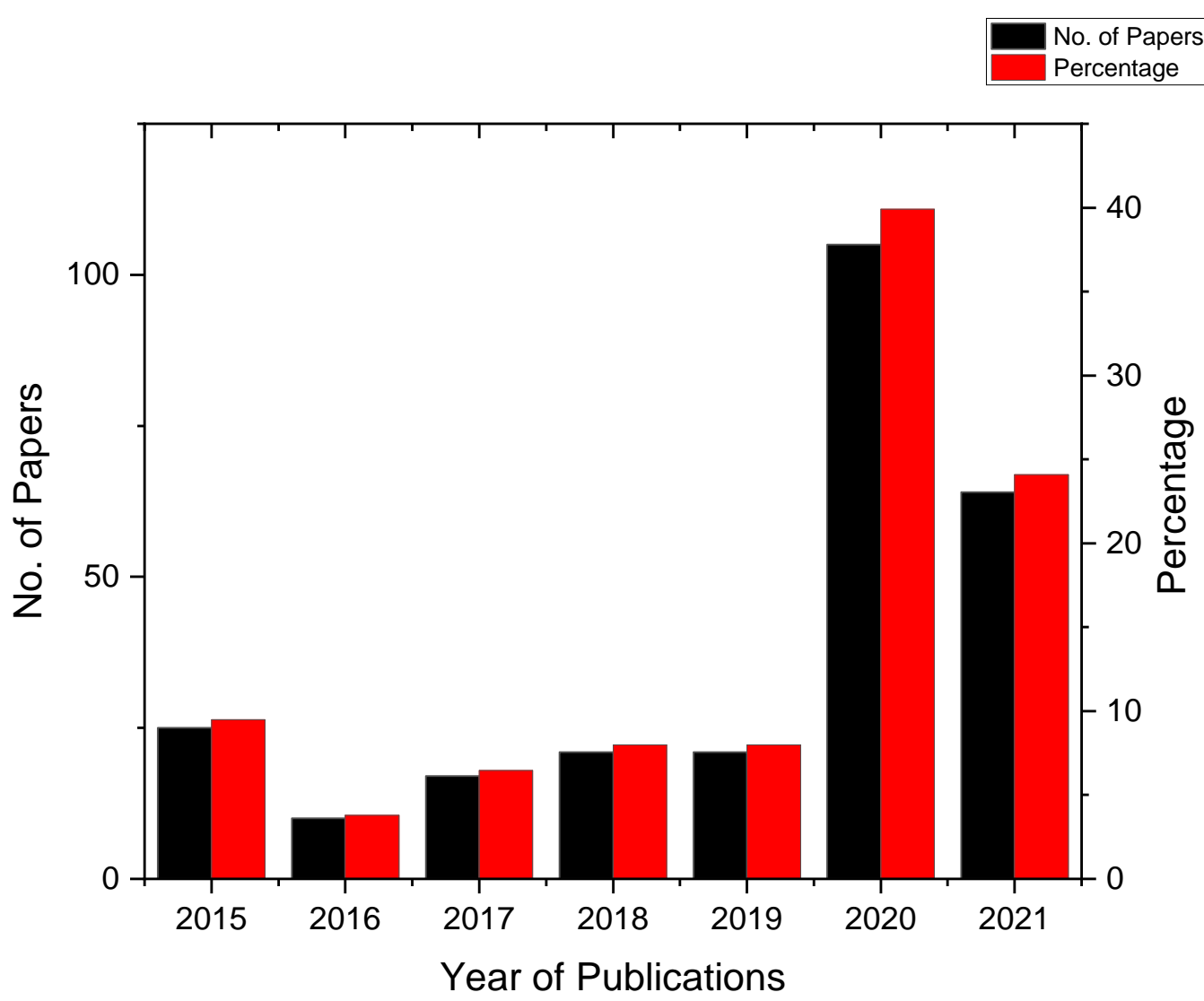

Figure 3. Publications in the last 6 years (2015-2021).

The illustration depicts that most of the research studies are based on the year 2020, with 105 articles counted. After 2020, 2021 is the most noticeable year, with 64 research articles. The second bar in the figure shows the percentage of the research articles that contributed to this review article. The percentage of research papers from the year 2020 is $40 \%$, and the remaining $60 \%$ cited articles from the remaining five years. These publishers and the selected journals are indexed by the web of science, and are well-known among the researchers, for instance, IEEE, Springer, MDPI, Google Scholar, and Elsevier. IEEE is the leading portal where articles and review papers were searched. A total of 107 research papers were selected from the IEEE database, which is the highest among all other search portals. For instance, $40.68 \%$ of selected research papers are from the IEEE portal. In addition, some of the research papers were searched using Google Scholar, Science Direct, and other research search portals. For instance, 56 papers were selected from Google Scholar and 32 journal papers from Elsevier. Research articles in other categories include less-known search engines such as Bing. These search portals include various publisher databases as illustrated in Figure 4. The selection criteria for publishers was their familiarity with the scientific community. 


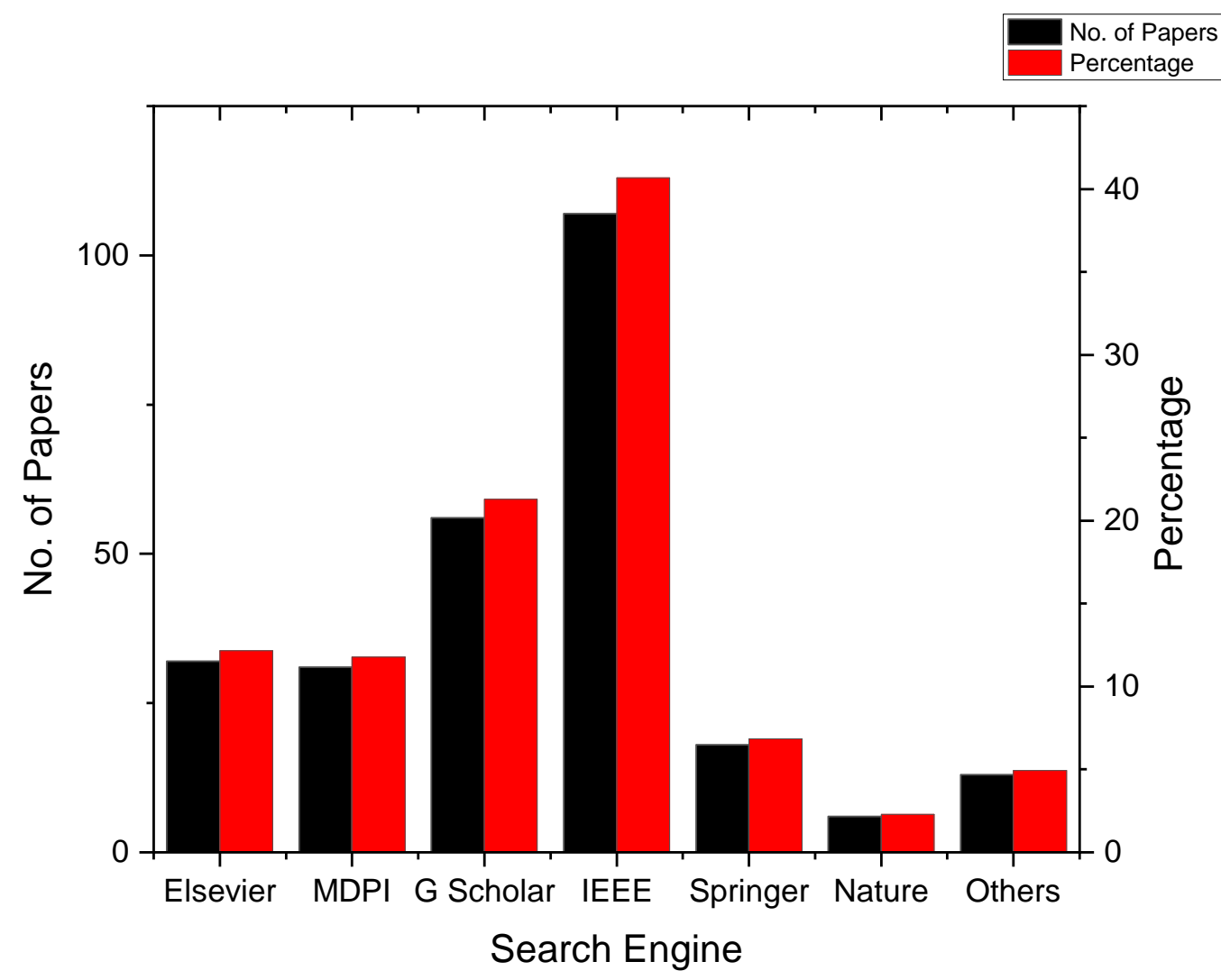

Figure 4. Research publishing websites used for research paper collection.

We analyzed the research papers based on the subject of the research articles. The collected articles are based on five major subject areas: machine learning, IoT, blockchain, healthcare, and COVID-19. The main focus of this study is the convergence mechanisms for tackling pandemic diseases such as COVID-19 using these emerging technologies. Most of the collected papers are based on IoT, with a total number of 102 articles. There are 63 collected articles associated with blockchain, 58 articles are proposed solutions based on the machine learning area, 35 research papers are based on the COVID-19 pandemic, and the five remaining papers are considered to be miscellaneous subject areas. Figure 5 presents the percentage analysis of the contribution based on subject areas.

Our study cites almost $72 \%$ of papers from the various web of science indexed journals and magazines, $19 \%$ from proceedings, $3 \%$ from books, and $6 \%$ from other sources such as websites. Figure 6 illustrates the comparative analysis research articles types.

The following keywords belong to the paper's central theme: IoT, COVID-19, blockchain, machine learning, adoption of blockchain in IoT, and artificial-intelligence-enabled IoT. Without the limitation on the scope of this topical review, the collected research papers from the literature review will be tremendous. Moreover, filtering and reducing the selected research papers is an extra benefit differentiating our research work from past studies and survey papers. Figure 7 shows the top journal papers cited in this work. Most of the journal articles have been collected from IEEE Access. 


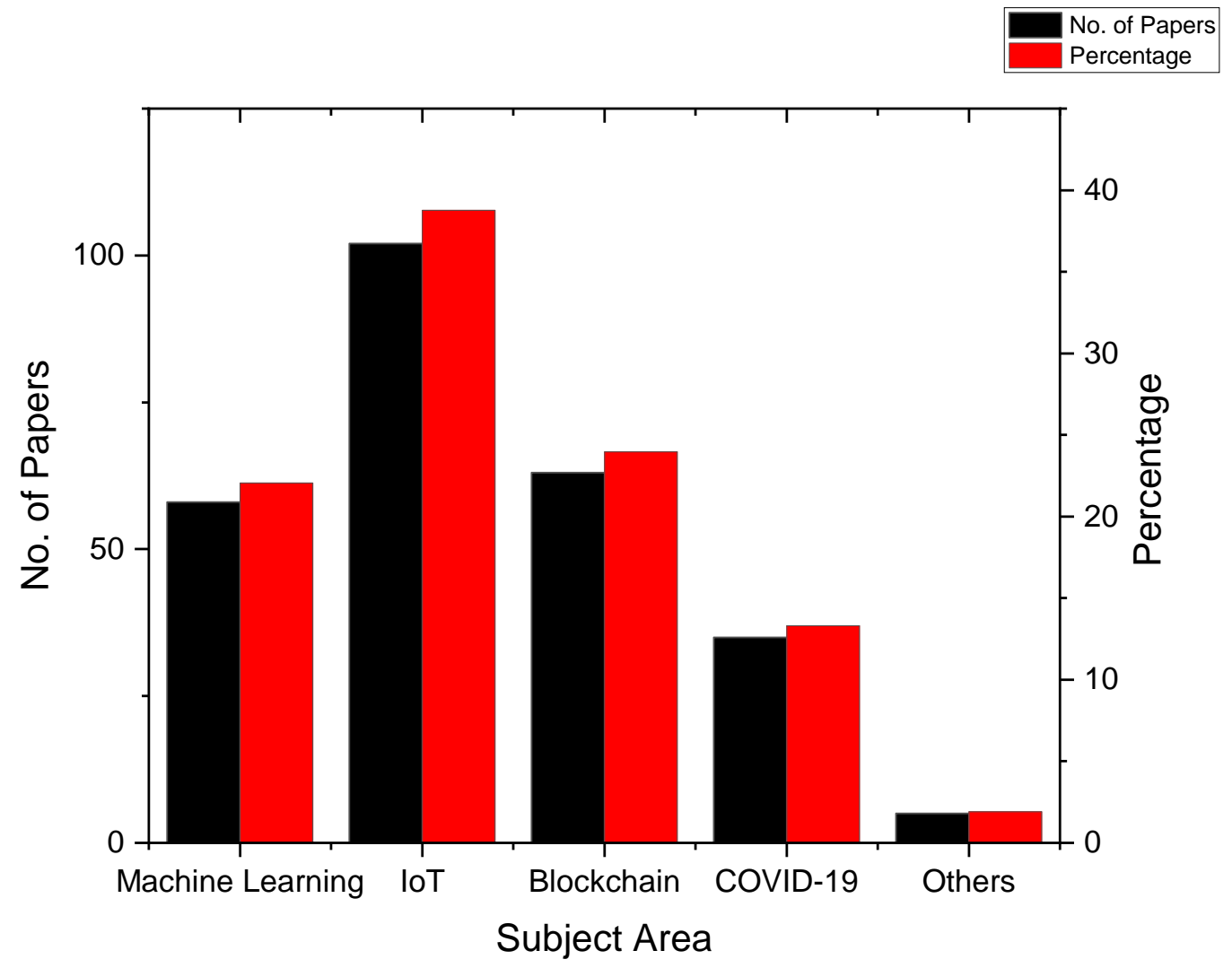

Figure 5. Research papers based on the subject area.

No. of Papers Percentage

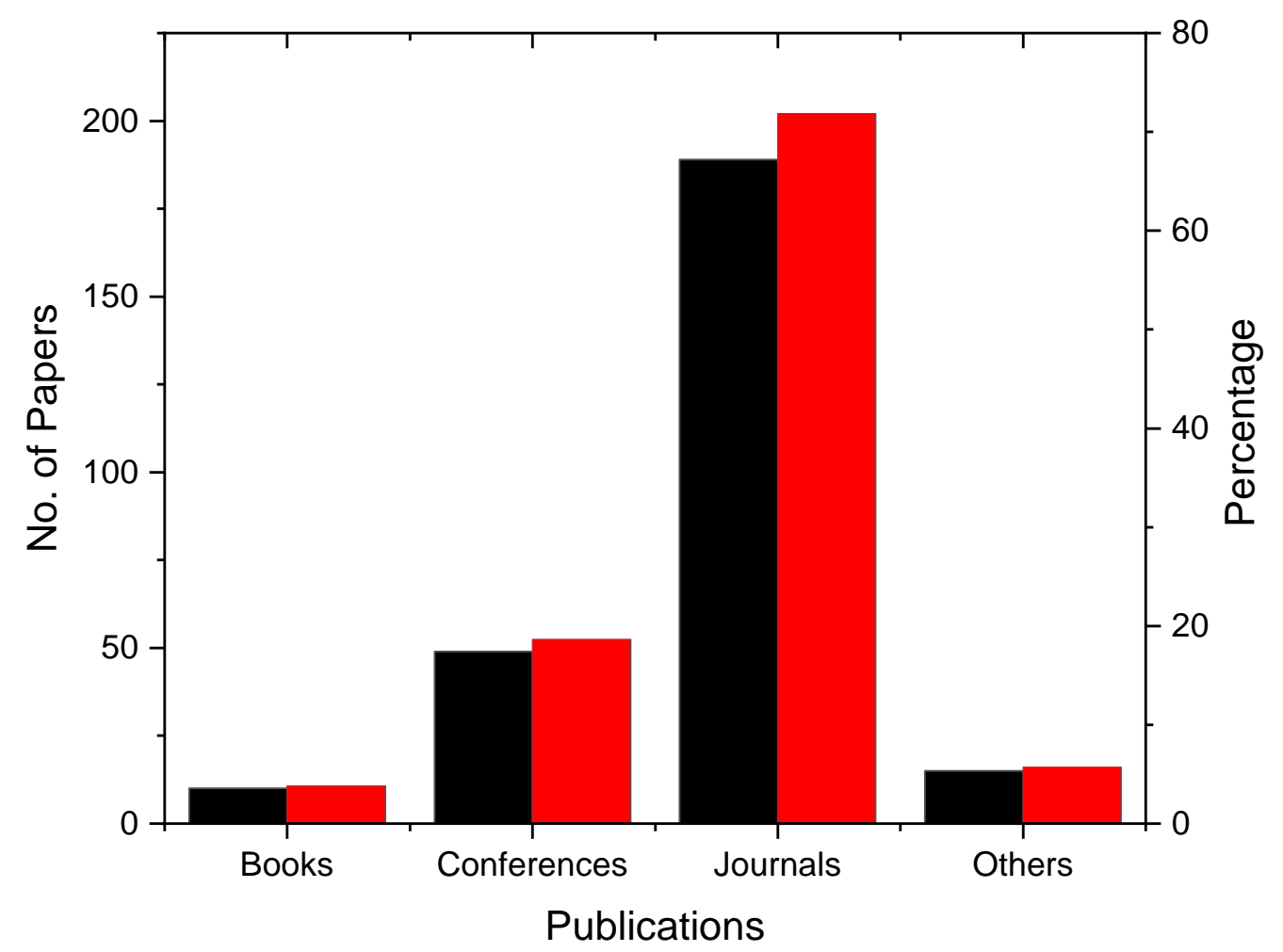

Figure 6. Research papers based on research articles types. 


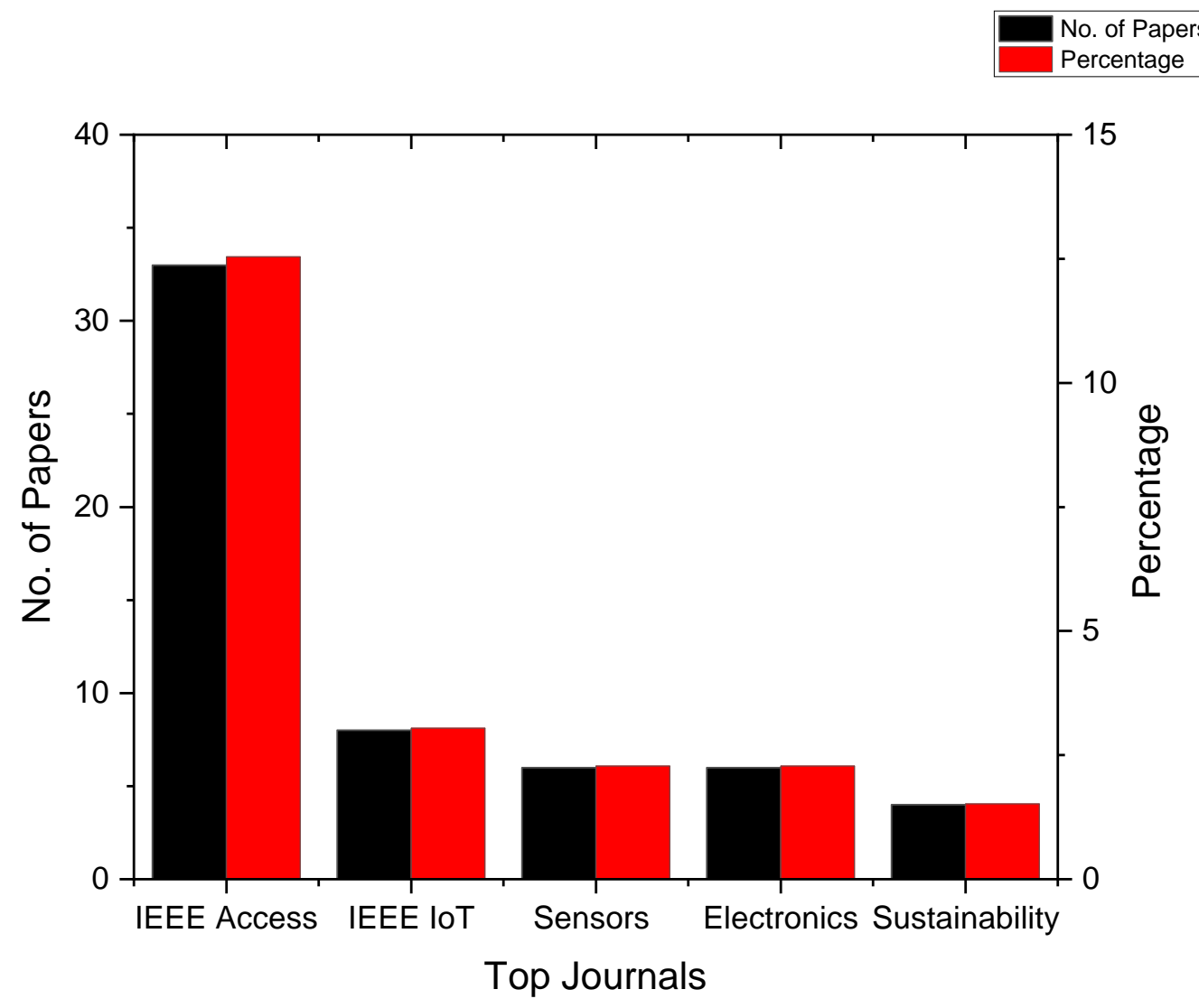

Figure 7. Research papers based on top-quality journals.

The most relevant research articles from the last couple of years were collected based on their top priority to perform effective analysis. Scholarly works older than two years were studied and utilized for background knowledge of the sections stated in this research. Research and survey papers with poor publisher and publication venue parameters were excluded; for instance, exclusion criteria include journal citation reports and other impact factors. This topical review paper preferred research papers that mainly focused on blockchain, machine learning, and IoT technologies to address the COVID-19 pandemic and other health-related challenges.

\section{Background}

IoT is acknowledged as one of the top emerging fields in the newest technologies, and its application is practical in various industries [36]. The IoT system provides communication between human-to-device, device-to-device, and human-to-human. IoT systems redefine the world where everything is connected and allows sharing data between humans with the help of electronic devices in a smart way [37]. Machine learning is a subtype of artificial intelligence and has become a vital technology in recent scientific studies. The progress and improvements in various areas, such as healthcare, banking, manufacturing, physics, chemistry, and bioinformatics, require innovative, intelligent techniques [38,39]. Nowadays, cryptocurrency is a very famous term in academic circles and businesses. It is a digital currency that can be used to buy goods and services. Bitcoin transactions could occur without any third party and are developed based on blockchain technology with a specially designed storing structure [40]. This section presents background studies of IoT, machine learning, and blockchain based on the recent web of science indexed literature.

\subsection{Internet of Things}

IoT integrates hundreds of thousands of physical devices through communication technologies and has brought immense revolutions in various research domains. IoT 
technologies focus on information service, understanding cognitive actions, and control of the real world by the equal number of connections between main and edge network [41]. IoT integrates cloud computing, sensor networks, electronic devices, mobile services based on advanced framework and information processing technologies. Many of us believe that IoT connects personal computers, tablets, smartphones, telephones, and servers; however, IoT connects sensors and actuators fixed in digital devices; usually, all devices are connected to the same internet protocol (IP). Smart home security, wireless inventory trackers, biometric scanners, and smart tennis rackets are some examples of IoT systems. These systems generate massive data that can be processed through statistical and machine learning analysis.

IoT applications are combined with blockchain technology in various areas such as insurance, education, healthcare, voting, stock exchange, to name a few. Blockchain is mainly used in smart cities where many IoT devices are placed in different locations. Adopting blockchain in IoT technology improves scalability, efficiency, robustness, time effectiveness, and computational cost-effectiveness. IoT generates data that can be stored in a blockchain managed by cloud-based servers. The authenticated users can access their private data from the cloud databases in a secure way $[42,43]$. IoT technologies identify integrated devices by unique internet protocol (IP) addresses using collections of transmission control protocol (TCP) and non-TCP. The approach of virtualizing electronic devices such as actuators and sensors into virtual objects is known as device virtualization [44-47]. IoT integrates virtual objects and electronic devices using transmission protocols such as WiFi, ZigBee, long-range wide area network (LoRaWAN), Bluetooth low energy (BLE), and Z-Wave, to name a few. The IoT devices have an adequate setup, and remotely available interfaces [48]. Latest research and development based on IoT introduces new terminologies, and IoT concepts such as artificial-intelligence-enabled IoT (AIoT), Internet of Anything (IoA), Internet of Everything (IoE), Industrial IoT (IIoT), Social IoT (SIoT), Web of Things (WoT), and machine-to-machine (M2M).

BLE is an enhanced version of Bluetooth, a widely used wireless method for a successful connection within 10 meters. Bluetooth 5.2 is the latest version that adds an advanced IP support profile. Research demonstrates that BLE is an entirely established and improved mechanism for IoT devices [49]. WiFi is a widely used internet protocol that communicates between IoT and physical devices. The communication range between most electronic devices is around $50 \mathrm{~m}$, which is five times greater than BLE communication [50]. ZigBee is also short-range wireless, which transfers protocol with a data transmission rate of $250 \mathrm{kbps}$. For a productive transmission of data between IoT devices, ZigBee is the most acceptable solution due to its security, high-level scalability, low-power consumption, and durability [51]. Z-Wave is a low-power transmission protocol that uses wireless frequency, fashioned for computerization systems such as sensors and lamp regulators. Z-wave can communicate protocol within 30-100 m; Z-wave is better than other protocols such as WiFi, Bluetooth, and ZigBee [52]. The LoRaWAN protocol is used for electrically powered long-range IoT devices for devices connectivity at long ranges using power. It recognizes the noise level of signals assumed from a threshold range. LoRaWAN is used by those applications where a huge number of devices are integrated for securely sharing of data using memory, and require minimal power consumption such as smart cities, smart hospitals, and smart homes [53-55].

The concept of IoE is presented by Cisco as the integration of global network data, humans, things, and devices [56-58]. The sharing of data between machine-to-machine as well as a human is known as M2M [59]. M2M automates sharing of information among machines without any human intervention [60]. Analyzing data, discovering resources, and managing devices are the main activities performed by these systems. A cloud and fog-based computing platform was deployed to the gateway layer for the management of services [61]. The edge node has a limited number of resources in edge computing (EC). Thus, relocation of computing resources to the cloud is necessary for performing huge and complex tasks [62,63]. Data trimming is considered a major issue in the Cloud of Things 
(CoT). Scientific community introduced efficient IoT architecture-based smart gateway to tackle the data trimming issue [64-66]. Data collection, pre-processing, data filtering, and data reconstruction into a more valued format are some of the operations performed by these smart gateways [67-69].

IT organizations are investing significantly in the development of fundamental IoT technologies due to strong economic potential. As a result, these organizations have introduced different IoT paid and open source applications in the last few years; however, a standard framework is required to introduce feasible IoT systems and overcome interoperability, heterogeneity, and diversity problems [70]. IoT applications have been implemented in many fields; the industrial area is considered the essential [71]. The fourth industrial revolution with IoT is named Industry 4.0, which integrates industrial observations using smart technologies. In industrial IoT applications, security and privacy are considered critical issues [72-74]. To handle and analyze these issues, Cisco, IBM, GE, and AT and T initiated a platform for the industrial IoT [75-77].

\subsection{Machine Learning}

Machine learning is a branch of artificial intelligence that provides data analysis that automates analytical model development. Machine learning can learn from data, identify patterns and make decisions with minimal human intervention. Advanced fields of machine learning, such as automated machine learning, further minimize human intervention by automating the model-building processes from preprocessing to model evaluation [78] The traditional software systems are developed in program code that rules the system behaviors; however, in machine learning, these rules are deduced from training data with machine learning algorithms. Machine learning algorithms automatically create rules according to the kind of data [79]. Subfields of machine learning based on the kinds of algorithms are supervised learning, unsupervised learning, semi-supervised learning, and reinforcement learning. Prediction and classification are examples of supervised learning, and clustering is an example of unsupervised learning.

Prediction is about expecting what will happen in the future, such as weather forecasting, future market performance, predicting heart disease using risk factors. On the other hand, classification recognizes class labels, i.e., handwritten digits, sentiment analysis, and identifying spam emails; therefore, prediction and classification are performed on labeled data. Unsupervised learning is based on unlabeled data. Clustering is an example of unsupervised learning; clustering is a task that divides similar data points or similar sets of objects into groups, usually of larger datasets [80]. For instance, Netflix uses an unsupervised learning algorithm for movie recommendation [81]. Machine learning is used as a supplementary technology in emerging technologies such as IoT and blockchain. For example, machine learning with blockchain in healthcare applications has been used for medical data analysis, remote patient monitoring, electronic health data management, biomedical study, pharmaceutical supply chain management, and education. Blockchain technology has produced flexibility in the last few years, leading to its integration in a vast range of systems, including healthcare and biomedical applications [82]. The integration of blockchain and machine learning in IoT can play a vital role in Industry 4.0 and the internet of health things [83,84].

\subsection{Background of Blockchain}

Blockchain is considered a public ledger and a type of database different from traditional databases such as relational databases in which data are stored. Instead, blockchain saves data in blocks and then chains them together with digital signatures in a distributed network. As new data comes, they pass into a new block. The distributed consensus and asymmetric cryptography algorithms have been implemented to achieve overall system reliability, ledger consistency, and user security. In addition, blockchain technology has some key attributes such as persistency, anonymity, auditability, and decentralization. These attributes can significantly reduce the cost and enhance efficiency. Some examples of 
financial services that use blockchain are digital assets, remittance, and online payment systems [31].

Additionally, blockchain can be applied in many other areas, such as IoT, public services, and security services. Transactions cannot be edited once put into the ledger since the blockchain is unchangeable. Organizations use blockchain for high reliability and security to attract customers [85-87]. Furthermore, blockchain can ignore the single point of failure issue since it is a distributed environment. To date, contemporary state-of-the-art techniques have presented various efforts on the adaptability of blockchain and machine learning in IoT applications [88]. IoT and network applications security has been addressed using mechanisms based on blockchain technology. Furthermore, machine learning models based on the huge amount of data collected from sensing devices are used to predict and classify different problems. Machine learning techniques coupled with advanced artificial intelligence techniques detect patterns in data. For instance, IoT-enabled applications integrate blockchain technologies with machine learning models to benefit medical report management, drug traceability, tracking infectious diseases, etc.

\section{Healthcare Applications}

The emergence of IoT, machine learning, and blockchain technologies have greatly enhanced healthcare systems' functionality and services. This section aims to review the application of IoT, machine learning, and blockchain in smart healthcare based on the web of science indexed journals. We also find out the key issues and future research areas in applying machine learning and blockchain technologies in healthcare systems based on IoT [89].

\subsection{IoT-Based Healthcare Applications}

IoT is revolutionizing healthcare systems and is a powerful platform for healthcare applications [90-92]. For instance, IoT combines thermal cameras and embedded sensors in electronic devices that collect data from essential points. IoT devices collect real-time health statuses and other patient information and then share these data with healthcare personnel. Patient health monitoring systems have the capability of monitoring patients by using the latest technologies [93-100]. In addition, it allows the sharing of patient records with the healthcare teams for data analysis. A healthcare system was proposed based on e-Health sensors for hospital management to examine patient health status and send the analysis to healthcare personnel [101]. The researchers used electrocardiogram (ECG) sensors to analyze heart functions, regulate the patient's condition, body temperature measuring, and acceleration sensing [102,103].

Moreover, the scientists used environmental sensors to measure the patient's room environment. For instance, Moghadas et al. [104,105] introduced a health application for arrhythmia patients based on an ECG device to analyze the heartbeat and applied the k-nearest neighbor (KNN) algorithm to predict the types of arrhythmia disease. A mobile application named Alzimio is used to confirm secure area hotspots and activity detection for patients affected by autism, Alzheimer's, and dementia diseases. It also allows medical teams to select specific actions, and unsafe zones receive warning signals when any crucial actions are detected. GPS is also utilized in many IoT devices to track patients and alert healthcare teams when the patient walks outside a specific zone [106]. An IoT-based application was developed to measure a soldier's health status by using body temperature, pulse rate sensors, and an oxygen analyzer. The system can track the soldier's live location based on GPS $[107,108]$. Summary of various IoT-based healthcare applications is shown in Table 3. 
Table 3. Summary of IoT-based healthcare applications.

\begin{tabular}{|c|c|c|c|}
\hline Title & Description & Advantages & Disadvantages \\
\hline $\begin{array}{l}\text { Super-resolution of Reti- } \\
\text { nal Images [109] }\end{array}$ & $\begin{array}{l}\text { Using multi-kernel SVR } \\
\text { for IoT healthcare applica- } \\
\text { tions. }\end{array}$ & $\begin{array}{l}\text { Processing retinal images, generate } \\
\text { good quality retinal images which help } \\
\text { image analysis. }\end{array}$ & $\begin{array}{l}\text { The IoT-based eye-care system required } \\
\text { minimal human intervention. }\end{array}$ \\
\hline SilverLink [110] & $\begin{array}{l}\text { Smart home health moni- } \\
\text { toring for senior care }\end{array}$ & $\begin{array}{l}\text { A home-based mobile health system for } \\
\text { reporting user activity and health status } \\
\text { and for approaching with family mem- } \\
\text { bers. Uses object and human sensors } \\
\text { for specifying a patient's health status. }\end{array}$ & $\begin{array}{l}\text { Average range of the object and human } \\
\text { sensors was determined to be approx- } \\
\text { imately } 7.3 \mathrm{~m} \text {, so signal transmission } \\
\text { stability required improvements. }\end{array}$ \\
\hline MOD-SET [111] & $\begin{array}{l}\text { Mobile diagnosis system } \\
\text { with emergency telecare } \\
\text { in Thailand }\end{array}$ & $\begin{array}{l}\text { Combination of emergency telehealth } \\
\text { and smartphone-based system in order } \\
\text { to find the nearest health center in case } \\
\text { of emergency. }\end{array}$ & $\begin{array}{l}\text { The system tested with a limited num- } \\
\text { ber of patients presenting conditions. }\end{array}$ \\
\hline $\begin{array}{l}\text { Smart space-based Ap- } \\
\text { proach [112] }\end{array}$ & $\begin{array}{l}\text { Assistance service system } \\
\text { for emergencies in person- } \\
\text { alized mobile healthcare }\end{array}$ & $\begin{array}{l}\text { An assistance service healthcare system } \\
\text { in emergencies for remote and mobile } \\
\text { patients. }\end{array}$ & $\begin{array}{l}\text { The system has needed overwhelming } \\
\text { human intervention. }\end{array}$ \\
\hline $\begin{array}{l}\text { Vital Signs Monitoring } \\
\text { [113] }\end{array}$ & $\begin{array}{l}\text { Salah activities recog- } \\
\text { nition model based on } \\
\text { smartphone. }\end{array}$ & $\begin{array}{l}\text { Correct or reject distorted signals of vi- } \\
\text { tal signs based on the data fusion ap- } \\
\text { proach. }\end{array}$ & $\begin{array}{l}\text { High energy consumption and static } \\
\text { platform for handling emergent condi- } \\
\text { tions. }\end{array}$ \\
\hline InterIoT [114] & $\begin{array}{l}\text { Active and assisted living } \\
\text { healthcare services sup- } \\
\text { port. }\end{array}$ & $\begin{array}{l}\text { Living mobile healthcare services in the } \\
\text { aspect of faster detection and correction } \\
\text { of critical situations. }\end{array}$ & $\begin{array}{l}\text { The performance evaluation of the inte- } \\
\text { grated platform is not yet presented. }\end{array}$ \\
\hline $\begin{array}{l}\text { Smartphone-centric Plat- } \\
\text { form [115] }\end{array}$ & $\begin{array}{l}\text { A remote health monitor- } \\
\text { ing platform for detecting } \\
\text { heart failure. }\end{array}$ & $\begin{array}{l}\text { Communicate through traditional } \\
\text { client-server systems, the hub of data } \\
\text { shared by sensors and smart proces- } \\
\text { sors, and autonomous sensors of the } \\
\text { patients' activity using a high-accuracy } \\
\text { motion detection algorithm. }\end{array}$ & $\begin{array}{l}\text { The current system is not capable of pre- } \\
\text { cisely computing the patients' pedes- } \\
\text { trian speed, and the integration be- } \\
\text { tween smartphones and other sensor } \\
\text { nodes is applied to other physical de- } \\
\text { vices. }\end{array}$ \\
\hline $\begin{array}{l}\text { H2U Healthcare System } \\
\text { [116] }\end{array}$ & $\begin{array}{l}\text { Intuitive IoT-based H2U } \\
\text { healthcare system for el- } \\
\text { derly patients }\end{array}$ & $\begin{array}{l}\text { A healthcare application to increase the } \\
\text { healthcare quality services, and can pro- } \\
\text { vide early treatment and recognize de- } \\
\text { teriorating conditions relatively early to } \\
\text { prevent the need for hospitalization. }\end{array}$ & $\begin{array}{l}\text { Privacy and security are vital treats } \\
\text { while the central patient database is } \\
\text { shared on the Internet. }\end{array}$ \\
\hline $\begin{array}{l}\text { Smart Healthcare System } \\
\text { for Isolated Areas [117] }\end{array}$ & $\begin{array}{l}\text { IoT-based smart health- } \\
\text { care monitoring system } \\
\text { for rural areas. }\end{array}$ & $\begin{array}{l}\text { To overcome the health issues facing in } \\
\text { rural/isolated areas. }\end{array}$ & $\begin{array}{l}\text { Demands } 24 \times 7 \text { connectivity where ru- } \\
\text { ral areas facing Internet issues such as } \\
\text { slow, expensive, and spotty. }\end{array}$ \\
\hline ECG Web Services [118] & $\begin{array}{l}\text { Patient health monitoring } \\
\text { in the Internet of Things. }\end{array}$ & $\begin{array}{l}\text { To diagnose body temperature, heart- } \\
\text { beat, and blood pressure using IoT- } \\
\text { based sensors. }\end{array}$ & $\begin{array}{l}\text { ECG reveals the heartbeat rate only dur- } \\
\text { ing the few seconds it takes to store the } \\
\text { tracing. }\end{array}$ \\
\hline $\begin{array}{l}\text { Patient Monitoring Sys- } \\
\text { tem [119] }\end{array}$ & $\begin{array}{l}\text { An IoT-based patient mon- } \\
\text { itoring system using Rasp- } \\
\text { berry Pi }\end{array}$ & $\begin{array}{l}\text { An effective monitoring patient's body } \\
\text { temperature, heartbeat, respiration rate, } \\
\text { and body movement using Raspberry } \\
\text { Pi board at a reduced cost. }\end{array}$ & $\begin{array}{l}\text { Shares all the health data of the partic- } \\
\text { ular patient to the web database. Any- } \\
\text { body can easily access the web and can } \\
\text { see the health information of patients. }\end{array}$ \\
\hline $\begin{array}{l}\text { ECG Monitoring System } \\
\text { [120] }\end{array}$ & $\begin{array}{l}\text { An IoT-cloud-based wear- } \\
\text { able ECG monitoring sys- } \\
\text { tem for smart healthcare }\end{array}$ & $\begin{array}{l}\text { High bandwidth rates for healthcare } \\
\text { data transmission, and web-based GUI } \\
\text { for versatile services. }\end{array}$ & $\begin{array}{l}\text { No scheduling mechanism for handling } \\
\text { emergent conditions of remote patients. }\end{array}$ \\
\hline Tracking COVID-19 [121] & $\begin{array}{l}\text { Anonymity preserving } \\
\text { IoT-based COVID-19 and } \\
\text { other infectious disease } \\
\text { contact tracing model. }\end{array}$ & $\begin{array}{l}\text { Send and receive alerts when people } \\
\text { are close to a confirmed case. }\end{array}$ & $\begin{array}{l}\text { The cost of scaling this solution is ex- } \\
\text { pensive, and the prototype smart con- } \\
\text { tract did not apply security and other } \\
\text { fine-grained solutions. }\end{array}$ \\
\hline NFS [122] & $\begin{array}{l}\text { NFC Based Public Health- } \\
\text { care Monitoring System }\end{array}$ & $\begin{array}{l}\text { To provide secure and reliable solutions } \\
\text { to a patient with long-term disorders. }\end{array}$ & $\begin{array}{l}\text { The system is not accessible to everyone } \\
\text { due to geographical barriers. }\end{array}$ \\
\hline
\end{tabular}

\subsection{Machine Learning Based Healthcare Applications}

Machine learning models have been used to detect patterns associated with diseases and health conditions. Usually, machine learning models are trained using historical datasets of healthcare records and other patient data. Recent advancements in machine 
learning technologies helped healthcare systems in developing countries to innovate sustainable solutions for chronic disease such has cancer diagnosis and treatment [123-125]. Machine learning algorithms are very effective in classifying complex patterns in data. Hence, machine learning algorithms are particularly used in medical applications, especially those medical application that depend on advanced proteomics and genomics analyses. Machine learning algorithms are fundamentally used in several disease detection and diagnosing problems. Machine learning models based on different algorithms are used in healthcare applications such as support vector machine (SVM), naïve Bayes (NB) classification, k-nearest neighbors (KNN), fuzzy logic, and classification and regression trees (CART) for different types of diseases [126,127].

Summary of research articles and reviews relevant to machine-learning-based healthcare applications are shown in Table 4.

Table 4. Summary of machine-learning-based healthcare applications.

\begin{tabular}{lll}
\hline Title & Accuracy & Relative Demerits \\
\hline $\begin{array}{l}\text { Heart diseases detection using } \\
\text { naive Bayes algorithm [128] }\end{array}$ & $86.41 \%$ & $\begin{array}{l}\text { The system is developed based on data mining models for clas- } \\
\text { sifying the data patterns and detecting the heart diseases and } \\
\text { considered as the best algorithm for many healthcare problems. } \\
\text { The naive Bayes algorithm performs positively with categorical } \\
\text { data but poorly with numerical data in the training set. }\end{array}$ \\
\hline
\end{tabular}

Diabetes diseases classification $95.83 \%, 95.24 \%$ using SVM and CNN [129]

\begin{tabular}{|c|c|c|}
\hline $\begin{array}{l}\text { Thyroid disease diagnosis using } \\
\text { SVM [130] }\end{array}$ & $97.49 \%$ & $\begin{array}{l}\text { Classify thyroid data using optimal feature selection and kernel- } \\
\text { based classifier process. Takes high computation time. }\end{array}$ \\
\hline $\begin{array}{l}\text { Breast cancer diagnosis using } \\
\text { four algorithms [131] }\end{array}$ & $\mathrm{SVM}=99.10 \%$ & $\begin{array}{l}\text { Assess the preciseness in classifying data concerning efficiency } \\
\text { and effectiveness of each algorithm. }\end{array}$ \\
\hline $\begin{array}{l}\text { Breast cancer prediction using } \\
\text { SVM and DT [132] }\end{array}$ & $91 \%$ & $\begin{array}{l}\text { An accurate prediction model for diagnosing breast cancer using } \\
\text { data mining techniques. }\end{array}$ \\
\hline $\begin{array}{l}\text { Diabetes Type-2 diagnosis using } \\
\text { six algorithms [133] }\end{array}$ & $\mathrm{RF}=94.10 \%$ & Forecasts the risk pertaining to diabetes mellitus type 2 . \\
\hline $\begin{array}{l}\text { Classification of breast cancer } \\
\text { data using J48 [134] }\end{array}$ & $95.00 \%$ & $\begin{array}{l}\text { The researchers discovered a method using the J48 decision tree } \\
\text { algorithm to automatically recognize if a tumor is malignant or } \\
\text { benign. The classification is performed through the analysis of } \\
\text { cell features extracted by the X-cyt program. }\end{array}$ \\
\hline $\begin{array}{l}\text { Breast cancer classification using } \\
\text { decision tree [135] }\end{array}$ & $\mathrm{J} 48=99 \%$ & $\begin{array}{l}\text { Analyzed best model for breast cancer data using decision tree } \\
\text { classification algorithms performance. }\end{array}$ \\
\hline $\begin{array}{l}\text { COVID-19 detection using SVM, } \\
\text { random forest, and K-NN [136] }\end{array}$ & $98.14,96.29,88.89 \%$ & $\begin{array}{l}\text { Detecting COVID- } 19 \text { patients by using machine learning algo- } \\
\text { rithms and chest X-ray images to prevent the spread of this pan- } \\
\text { demic as soon as possible. }\end{array}$ \\
\hline $\begin{array}{l}\text { Swallowing detection using DT, } \\
\text { SVM, and NN [137] }\end{array}$ & $93.2,86.2,93.7 \%$ & $\begin{array}{l}\text { Achieved high accuracy binary swallowing recognition from au- } \\
\text { dio recordings using machine learning algorithms. }\end{array}$ \\
\hline $\begin{array}{l}\text { Kidney disease diagnosis using } \\
\text { SVM [138] }\end{array}$ & $93 \%$ & $\begin{array}{l}\text { Diagnosis of kidney disease using machine learning algorithms } \\
\text { based on laboratory tests, clinical history, and physical tests that } \\
\text { are cheap, safe, and noninvasive. }\end{array}$ \\
\hline $\begin{array}{l}\text { Kidney disease diagnosis using } \\
\text { CNN-SVM [139] }\end{array}$ & $98.04 \%$ & $\begin{array}{l}\text { The proposed sensing module can be used with the skills of deep } \\
\text { learning for recognizing CKD dataset more efficiently than exist- } \\
\text { ing techniques. }\end{array}$ \\
\hline $\begin{array}{l}\text { Kidney disease diagnosis using } \\
\text { six algorithms [140] }\end{array}$ & $\mathrm{RF}=99.75 \%, \mathrm{LR}+\mathrm{RF}=99.83 \%$ & $\begin{array}{l}\text { Suitable regarding samples and imputation diagnosis. The gen- } \\
\text { eralization performance might be limited due to relatively small } \\
\text { available data samples in model development. The model cannot } \\
\text { identify the severity of CKD because there are only two groups of } \\
\text { data samples in the dataset, such as CKD and NOTCKd. }\end{array}$ \\
\hline $\begin{array}{l}\text { Alzheimer's disease diagnosis } \\
\text { using five algorithms [141] }\end{array}$ & $\mathrm{NN}=98.36 \%$ & $\begin{array}{l}\text { Identifies of Alzheimer's in its initial stage by applying machine } \\
\text { learning algorithms. It will reduce the chances of creating further } \\
\text { complications of Alzheimer disease patients. }\end{array}$ \\
\hline
\end{tabular}

Used transfer learning from $\mathrm{CNN}$ as the input features for classification using the SVM that reduces the executed time required by the classification process using $\mathrm{CNN}$ with fine-tuning. Only 2 out of $8 \mathrm{CNN}$ architectures give $90+$ accuracy due to the small dataset.

Classify thyroid data using optimal feature selection and kernelAssess the preciseness in classifying data concerning efficiency and effectiveness of each algorithm. data mining techniques.

Forecasts the risk pertaining to diabetes mellitus type 2 .

The researchers discovered a method using the J48 decision tree algorithm to automatically recognize if a tumor is malignant or benign. The classification is performed through the analysis of cill program. classification algorithms performance.

ning algodemic as soon as possible.

Achieved high accuracy binary swallowing recognition from auDiagnosis of kidney disease using machine learning algorithms based on laboratory tests, clinical history, and physical tests that are cheap, safe, and noninvasive.

Suitable regarding samples and imputation diagnosis. The generalization performance might be limited due to relatively small available data samples in model development. The model cannot identify the severity of CKD because there are only two groups of data samples in the dataset, such as CKD and NOTCKd.

learning algorithms. It will reduce the chances of creating furthe 
Machine learning algorithms have been used to diagnose heart disease based on publicly available datasets from UCI machine learning repository. SVM and multi-layer perceptron have been used for heart disease prediction [142]. Multi-layer perceptron algorithm offers $90.57 \%$ accuracy, and SVM provides $92.45 \%$ accuracy for two-class problem. Likewise, the multi-layer perceptron algorithm achieves $68.86 \%$ accuracy, and SVM provides $59.01 \%$ accuracy for five class problems. Many machine learning algorithms are used to increase the accuracy of diabetes disease analysis based on datasets from UCI machine learning repository. Researchers proposed a machine learning technique for diagnosing diabetes by applying the NB algorithm and decision trees. The NB algorithm offers $79.56 \%$ accuracy, and the decision tree algorithms' accuracy is $76.95 \%$. Machine learning algorithms such as SVM and decision trees were also applied to predict thyroid diseases by using dataset from UCI machine learning repository [143]. For instance, Begum et al. [144] proposed an advanced system based on data mining algorithms for diagnosing thyroid disorder.

\subsection{Blockchain Based Applications in Healthcare}

Blockchain has extensive healthcare applications and ledger technology aids the secure transmission of patient medical data, maintains the medicine supply chain [145]. A summary of different research papers and reviews related to blockchain-based healthcare applications is shown in Table 5.

Table 5. Summary of blockchain-based healthcare applications.

\begin{tabular}{|c|c|c|c|}
\hline Topic & Description & Advantages & Disadvantages \\
\hline $\begin{array}{l}\text { Blockchain for COVID-19 } \\
{[82,146]}\end{array}$ & $\begin{array}{l}\text { Blockchain and AI Tech- } \\
\text { nology for COVID-19 }\end{array}$ & $\begin{array}{l}\text { Self-testing blockchain and artificial- } \\
\text { intelligence-based system for COVID- } \\
19 \text { outbreak. }\end{array}$ & $\begin{array}{l}\text { Relevant stakeholders' involvement } \\
\text { will be crucial to ensure the proposed } \\
\text { system's efficient implementation and } \\
\text { viable development. }\end{array}$ \\
\hline $\begin{array}{l}\text { Tracing agri-food using } \\
\text { BC [147] }\end{array}$ & $\begin{array}{l}\text { Walmart's pork and } \\
\text { mango pilots with IBM }\end{array}$ & $\begin{array}{l}\text { Deployed blockchain solutions } \\
\text { throughout the global food ecosystem } \\
\text { to increase safety and reduce waste. }\end{array}$ & $\begin{array}{l}\text { Recreation of the supply chain is not } \\
\text { present in IBM's blockchain solution. }\end{array}$ \\
\hline Smart Provenance [148] & $\begin{array}{l}\text { A distributed blockchain- } \\
\text { based data provenance } \\
\text { system }\end{array}$ & $\begin{array}{l}\text { Provides reliable data source collection, } \\
\text { verification, and management. }\end{array}$ & Not completely secure. \\
\hline $\begin{array}{l}\text { Electronic healthcare us- } \\
\text { ing blockchain [149] }\end{array}$ & $\begin{array}{l}\text { Blockchain-based elec- } \\
\text { tronic healthcare record } \\
\text { system for healthcare } 4.0 \\
\text { applications. }\end{array}$ & $\begin{array}{l}\text { Utilizing ACP algorithms to improve } \\
\text { data sharing between healthcare } \\
\text { providers. }\end{array}$ & $\begin{array}{l}\text { Lower TPS on large block size and } \\
\text { Higher TPS on small block size reduced } \\
\text { performance of the system. }\end{array}$ \\
\hline BAKMP-IoMT [43] & $\begin{array}{l}\text { Design of blockchain- } \\
\text { enabled authenticated key } \\
\text { management protocol for } \\
\text { internet of medical things } \\
\text { deployment }\end{array}$ & $\begin{array}{l}\text { Provides secure management among } \\
\text { health devices and local servers and } \\
\text { cloud servers. }\end{array}$ & $\begin{array}{l}\text { Entire health data stores in cloud } \\
\text { servers (Data backup). }\end{array}$ \\
\hline MBPA [150] & $\begin{array}{l}\text { A MediBchain-based } \\
\text { privacy-preserving mu- } \\
\text { tual authentication }\end{array}$ & $\begin{array}{l}\text { A privacy-preserving joint verification } \\
\text { system for mobile medical cloud archi- } \\
\text { tecture. }\end{array}$ & $\begin{array}{l}\text { MediBchain-based } \\
\text { threats. }\end{array}$ \\
\hline MedChain [151] & $\begin{array}{l}\text { Blockchain-based system } \\
\text { for medical records access } \\
\text { and permissions manage- } \\
\text { ment }\end{array}$ & $\begin{array}{l}\text { Time-based smart contracts are used to } \\
\text { handle transactions and access to health } \\
\text { data. }\end{array}$ & High cost. \\
\hline BIoMT [152] & Blockchain for IoMT & $\begin{array}{l}\text { A light Blockchain-based model focus- } \\
\text { ing to secure the Internet of Medical } \\
\text { Things (IoMT). }\end{array}$ & Interoperability. \\
\hline $\begin{array}{ll}\text { Blockchain } & \text { distributed } \\
\text { ledger [153] } & \end{array}$ & $\begin{array}{l}\text { Blockchain distributed } \\
\text { ledger technologies for } \\
\text { biomedical and health } \\
\text { care applications. }\end{array}$ & $\begin{array}{l}\text { Introducing blockchain platforms to the } \\
\text { health care and biomedical domains. }\end{array}$ & $\begin{array}{l}\text { Consumes too much energy, no fault- } \\
\text { tolerance. }\end{array}$ \\
\hline
\end{tabular}


Table 5. Cont.

\begin{tabular}{|c|c|c|c|}
\hline Topic & Description & Advantages & Disadvantages \\
\hline $\begin{array}{l}\text { Blockchain for Healthcare } \\
\text { [154] }\end{array}$ & $\begin{array}{l}\text { Blockchain technology for } \\
\text { healthcare: facilitating the } \\
\text { transition to patient-driven } \\
\text { interoperability. }\end{array}$ & $\begin{array}{l}\text { Expedites data liquidity, aggregation, im- } \\
\text { mutability, access rules, and identity. }\end{array}$ & $\begin{array}{l}\text { Privacy and security considerations, scala- } \\
\text { bility. }\end{array}$ \\
\hline $\begin{array}{l}\text { EMR data sharing using } \\
\text { blockchain [155] }\end{array}$ & $\begin{array}{l}\text { Secure and trustable EMR } \\
\text { sharing using blockchain }\end{array}$ & $\begin{array}{l}\text { Blockchain-based medical data manage- } \\
\text { ment and sharing for cancer patient care. }\end{array}$ & $\begin{array}{l}\text { The structure of patient data and their meta- } \\
\text { data are insufficient. }\end{array}$ \\
\hline $\begin{array}{l}\text { Tamper-resistant mobile } \\
\text { health [156] }\end{array}$ & $\begin{array}{l}\text { Tamper-resistant mobile } \\
\text { health using blockchain } \\
\text { technology }\end{array}$ & $\begin{array}{l}\text { Introduces blockchain-based system, which } \\
\text { allows trusted and auditable computing. }\end{array}$ & $\begin{array}{l}\text { Poorly maintained and outdated codes pro- } \\
\text { vide vulnerability, and the theoretical limi- } \\
\text { tation of the consensus model has flaws. }\end{array}$ \\
\hline $\begin{array}{l}\text { Secure sharing of health im- } \\
\text { ages [157] }\end{array}$ & $\begin{array}{l}\text { Secure and decentralized } \\
\text { sharing of medical imag- } \\
\text { ing data via blockchain } \\
\text { consensus }\end{array}$ & $\begin{array}{l}\text { Removes third-party access to safeguard } \\
\text { medical data. }\end{array}$ & $\begin{array}{l}\text { Patient-specific issues, the ability to share } \\
\text { data does not alone ensure its usability. }\end{array}$ \\
\hline $\begin{array}{l}\text { Governing drug supply } \\
\text { chain [158] }\end{array}$ & $\begin{array}{l}\text { Governance on the drug } \\
\text { supply chain via gcoin } \\
\text { blockchain. }\end{array}$ & $\begin{array}{l}\text { Creating transparent transactions of drug } \\
\text { data using Gcoin blockchain to prevent } \\
\text { counterfeit drugs, to protect public health. }\end{array}$ & $\begin{array}{l}\text { Not a cost-benefit, less consultant to key } \\
\text { stakeholders. }\end{array}$ \\
\hline $\begin{array}{l}\text { Healthcare blockchain for se- } \\
\text { cure RPM [159] }\end{array}$ & $\begin{array}{l}\text { Healthcare blockchain sys- } \\
\text { tem using smart contracts }\end{array}$ & $\begin{array}{l}\text { Support real-time patient monitoring and } \\
\text { health status. }\end{array}$ & $\begin{array}{l}\text { Key management issue, not be used for } \\
\text { emergency response, as the delay might in- } \\
\text { crease response time. }\end{array}$ \\
\hline OmniPHR [160] & $\begin{array}{l}\text { A distributed architecture } \\
\text { model to integrate personal } \\
\text { health records. }\end{array}$ & $\begin{array}{l}\text { Combining PHRs for patients and medical } \\
\text { teams using a distributed model. }\end{array}$ & $\begin{array}{l}\text { Possibility of occurring duplicate data entry, } \\
\text { not fully secured, patient's data that are not } \\
\text { in the model's scope will not be part of the } \\
\text { sharing. }\end{array}$ \\
\hline
\end{tabular}

This system is based on a public blockchain that guarantees confidentiality and validity. The single point failure system is handled in the proposed system. A pioneer research work in EMR management applications is presented, which addresses the issue of scalability and data encryption [161]. Nevertheless, the proposed system still faces some shortcomings. Liang et al. [162] presented a mobile application to collect patient data and to share between medical teams, insurance companies, and patients. A private blockchain was used as a solution for privacy and access control. The efficiency and scalability problems of data processing were also addressed in the proposed system [162].

Many research papers have been proposed to monitor and trace health and medical products data. For instance systems were proposed to combine drug supply chains with blockchain throughout transportation. For example, Bocek et al. [163] implemented an Ethereum blockchain-based system for storing data of drug supply chain and provide publicly available data with immutability considerations. Thermal sensitive devices are introduced in this system to share temperature data throughout the transportation of medical commodities. A rule is defined in a smart contract for exact temperature requirements, and to confirm the submission of temperature data for every new consignment. Huang et al. [164] suggested a drug ledger system based on blockchain configured for medical product traceability and regulation.

Figure 8 presents conceptual reference layer architecture for leveraging the abovementioned technologies for healthcare applications development based on IoT, machine learning, and blockchain.

The reference layered architecture consists of several layers. The device layer consists of medical sensing and actuating devices. The virtualization layer virtualizes all devices connected to the IoT platform into virtual objects. Data owners' layers present the data generated by patients and electronic health record systems from the IoT platform. The data provider layer provides data to local blockchain and data storage systems and other data providers. Local blockchains and a central federated blockchain network allow the interconnecting of healthcare institutions and IoT orchestrating platforms. The reference layered architecture is designed to support healthcare stakeholders such as the data broker, computing, machine learning, and service provider. The data provider layer aims to share 
data faster, securely, and without losing essential, trusted properties such as accountability, traceability, and data privacy.

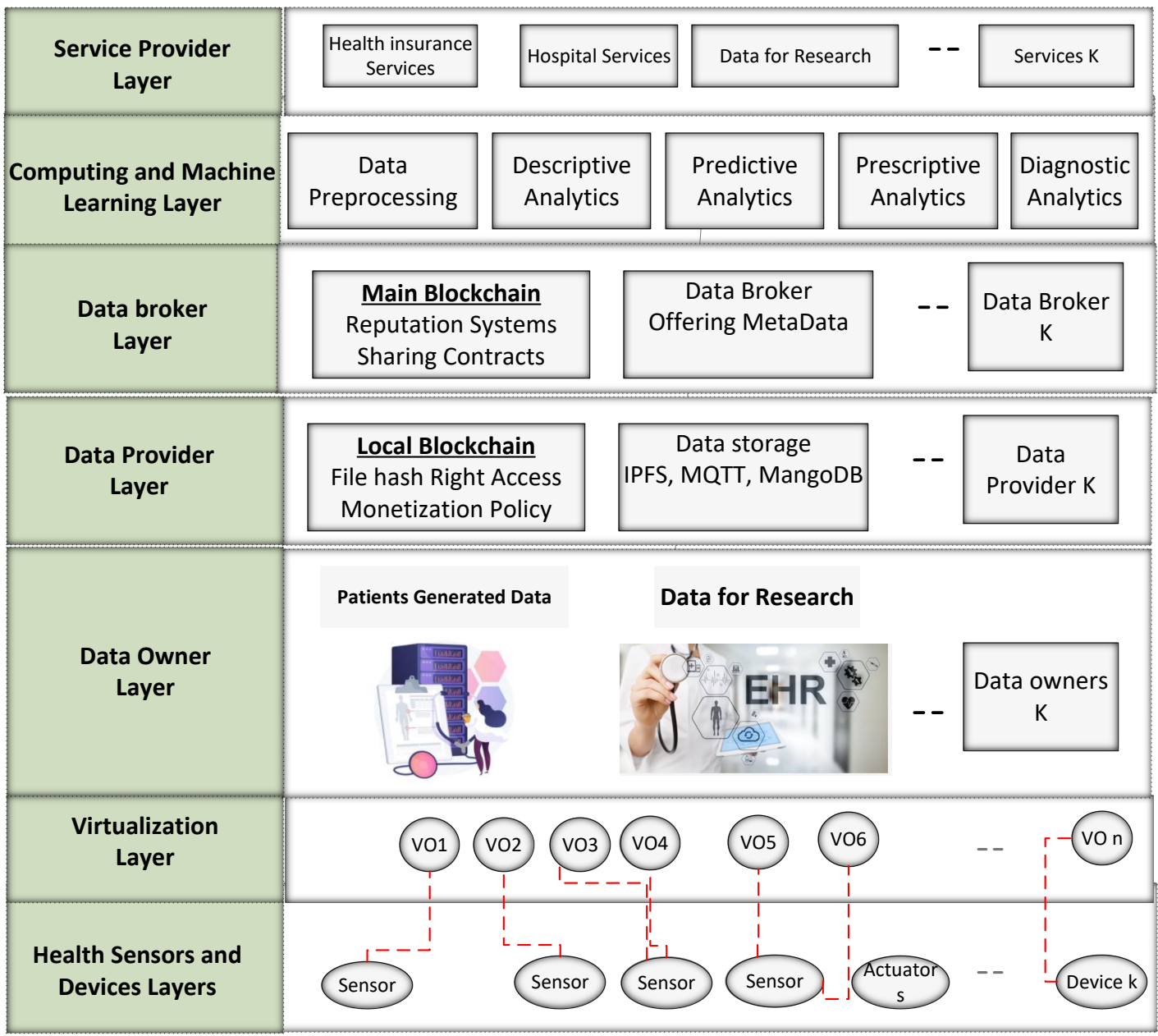

Figure 8. Conceptual layered architecture of IoT, blockchain, and machine learning for healthcare applications.

\section{Leveraging Technologies for COVID-19 and Future Pandemics}

Machine learning algorithms could be widely used to detect and notify deteriorating conditions in IoT and blockchain-based clinical and public health applications. These intelligent service management mechanisms can provide decision-making to manage the impacts of chronic diseases and pandemics effectively. This section aims to identify the case study of the COVID19 pandemic involving machine learning, IoT, and blockchain for pandemic readiness and response from the literature. World health organization (WHO) and centers for disease control and prevention (CDC) stated that digital technologies could play an essential role in enhancing health policy regarding COVID-19 disease [165]. Blockchain, machine learning, and IoT are the leading technologies to establish solutions for the different diseases $[166,167]$. The integration of artificial intelligence and IoT brings a new range of possibilities, even though AIoT is a new idea. The UAVs equipped with IoT sensors can collect raw data to make smart decisions without any human involvement. The scientific community considers thermal cameras as the best tools for data collection.

Nowadays, more systematic methods are needed to detect COVID-19 patients. In addition, healthcare organizations in developing countries face problems during testing COVID-19 patients due to a lack of testing kits. Another problem is privacy concerns in data sharing across different healthcare organizations. Solution based on CT images was proposed for detecting COVID-19 patients [168]. Firstly, they proposed a data normal- 
ization method that acts towards data heterogeneity as the data are collected from many healthcare organizations with various CT devices. A capsule network-based classification and segmentation mechanism is used for diagnosing COVID-19 patients. The proposed mechanism can train a general model using blockchain with a federated leaning to maintain the organization's privacy. In addition, the developed solution utilizes recent data for enhancing CT images diagnosis and detection accuracy. Remarkable applications of emerging technologies used to defeat COVID-19 are discussed in the upcoming subsection [169-171].

\subsection{COVID-19}

In December 2019, a pandemic epidemiologically associated with the Seafood Wholesale Market was reported in Wuhan, China. On the 12 March 2020, the World Health Organization declared a coronavirus disease (COVID-19) pandemic due to its rapid escalation. Since then, the world has experienced a significant increase in deaths and economic turmoil. Moreover, the pandemic has now reached more than 200 countries around the globe. Because of giant positive single-stranded RNA viruses, coronaviruses affect humans as well as animals. "Tyrell" and "Bynoe" discovered coronaviruses in 1966 by refining viruses from regular cold patients. There are four subgroups of coronavirus, namely, ALPHA, BETA, GAMMA, and DELTA. Mammals, specifically bats, cause ALPHA and BETA viruses, whereas birds and pigs cause GAMMA and DELTA. The BETA virus can lead to significant infection or possibly death, whereas the ALPHA virus causes symptom-less diseases. SARS-COV-2 is from the B lineage of the BETA version of coronavirus and is nearly associated with the SARS-COV virus [172]. In Wuhan, SARS-COV-2 seemingly resulted from a transmission from animals to humans. The early medical reports of the SARS-CoV-2 related to COVID-19 was pneumonia. Furthermore, current clinical signs also indicate gastrointestinal and symptom-less infections, mostly among young kids. The number of affected peoples who remain asymptomatic during the period of the disease is still to be measured. The manifestations of the pandemic in symptomatic patients typically start within a week, including fever, nasal congestion, cough, fatigue, and other symptoms of breath contamination. Pneumonia commonly arises between the second and third week of an asymptomatic virus. Unusual symptoms of virus-related pneumonia include showing changes through chest $X$-rays, reduced oxygen saturation, blood gas divergence, and other approaches [173]. Different diseases caused by coronavirus are mentioned in Table 6.

Table 6. Human diseases caused by the coronavirus.

\begin{tabular}{lll}
\hline S.No & Disease & Virus \\
\hline 1 & Common Cold & HCoV-229E [174-176] \\
2 & Common Cold & HCoV-HKU1 [177-179] \\
3 & Common Cold & HCoV-NL63 [180-182] \\
4 & Common Cold & HCoV-OC43 [183-185] \\
5 & MERS & MERS-CoV [186,187] \\
6 & SARS & SARS-CoV-1 $[187-190]$ \\
7 & COVID-19 & SARS-CoV-2 [172,187,191-194] \\
\hline
\end{tabular}

The spreading ratio of both SARS and MERS is less than COVID-19 [195]. Anyhow, the number of cases in COVID-19 has outnumbered the number of cases in both MERS and SARS.

\subsection{IoT-Based Technologies to Mitigate COVID-19 Challenges}

IoT is leading research and analysis platforms in various academic and industrial areas, especially in health. The accelerated development in IoT technologies can remodel current healthcare systems by integrating social, economic, and technological views. For example, the COVID-19 pandemic has affected the world's economy since December 2019. The combination of artificial intelligence, blockchain, and IoT technology can help 
combat the COVID-19 pandemic. An application healthcare application based on IoT and artificial intelligence for diagnosing COVID-19 patients and detecting it at early stages was introduced [196]. The system's goal is to minimize direct interaction with COVID19 patients with the help of several smart sensors such as blood sensors, pulse sensors, and thermal monitoring. The researchers introduced a COVID-19 detection and tracking application that collects real-time data from wearable sensors and mobile apps and then applied machine learning algorithms to analyze, classify, and predict the collected datasets. Moreover, an IoT-based framework utilizing smartwatches, infrared thermometers, optical and IP cameras is proposed to minimize the COVID-19 outbreak [197]. The sensors are operating automatically without any human involvement. The application operates in the following phases. In the first step, the application measures the patient's temperature using thermal sensors. Then, the pulse sensor measures the heartbeat if the patient has a specific temperature. Next, the blood sensor measures platelets and blood cell levels. Finally, if the patient has tested positive, they must be isolated for further tests and quarantine protocols.

\subsubsection{Tracking COVID-19 Using Smart Thermometers}

In 2012, a health company in the USA named Kinsa presented a smart thermometer to diagnose high fever patients. Smart thermometers were initially proposed to diagnose the common cold. Nonetheless, it is used to track COVID-19 patients effectively. Kinsa Health has arranged approximately a million smart thermometers for families in different states of the US during the COVID-19 pandemic. These smart thermometers are connected with a mobile application to monitor health status. Kinsa health company then combines the collected data to illustrate daily-based graphs of the US states that observe a high-temperature rise. Thus, allowing health organizations in the US to detect possible flashpoints. These charts have been proven to be more accurate in detecting the spread of fever throughout the US in recent times. In addition, Kinsa's smart thermometer is more reliable than CDC's official app concerning the performance of prediction [198].

\subsubsection{Battery-Operated Buttons}

Many health sectors in Canada have deployed IoT buttons known as Wanda Quick Touch to reduce the number of hospital-acquired infections (HAIs). Given below are the features that IoT buttons were designed for:

- Fast in any service,

- Regardless of their size,

- To send quick alerts to the management team,

- Notifying any health problem that can generate a risk to citizens' protection.

An excellent functionality of IoT buttons is their independence on exterior structure, for example, their capability to stick to some specified aspect [199].

\subsubsection{Drone Technologies}

Drones may be used to track those peoples who came in contact with the virus-infected person [200]. Drones can support tracking infected people who are leaving quarantine early as well as enforce individuals to wear masks. Recently, drones were used in Europe and the USA to confirm that social distancing and lockdown laws were strictly followed or not [201]. Camera-fitted drones were deployed to issue guidelines and cautions to persons for violating rules of COVID-19-related lockdowns and procedures [201,202]. Moreover, drones were deployed in remote inspecting of infected residents and extremely contaminated regions. Drones have been used to provide the necessary equipment to medical teams as well as collect and share tracks for verification during nearby services. 


\subsubsection{Telehealth in a Pandemic}

The usage of the Internet of Medical Things (IoMT) mechanism to provide remote patient monitoring (RPM) is called telehealth, also known as telemedicine. It allows healthcare providers to predict, identify, and medicate patients without requiring any physical contact $[203,204]$. Several telehealth technologies and IoMT platforms are facing challenges due to rapid overload on servers. An e-commerce technology for healthcare problems named JD Health has reported a significant increment in requests for the online meeting due to the rapid spread of COVID-19 [205]. Table 7 shows telehealth mechanisms are being implemented in many countries to control the influence of COVID-19. Two key benefits of implementing telemedicine approaches are minimizing the load on the overworked medical personnel. It reduces the risk of the transformation of disease from patient to hospital staff.

Table 7. Telemedicine platforms implemented to control the impact of COVID-19.

\begin{tabular}{lll}
\hline Country & Organization & References \\
\hline United States of America & George Washington University Hospital (GWUH) & {$[206]$} \\
United States of America & Rush University Medical Center & {$[207]$} \\
India & The state governments of Andhra Pradesh and Assam & {$[208,209]$} \\
Israel & Sheba Medical Center & {$[210,211]$} \\
\hline
\end{tabular}

\subsection{Machine Learning Technologies to Mitigate COVID-19 Challenges}

Machine learning stands to be the most suitable technology to defeat COVID-19 disease efficiently [212]. Machine learning has been verified to be an innovative technological development. The scientific community presents remarkable research on machine learning that can support healthcare organizations to efficiently contend the COVID-19 disease [213-217].

\subsubsection{Face Recognition System}

Thermal imaging with face detection is used in the first step of the proposed work [21]. The suspected patient is required to be tested to confirm the indefinite disease. According to researchers, the face recognition system identifies a person and is labeled with a name in four steps. Localization of a person's face in an image is the first step in the pipeline using a method called histogram of oriented gradients (HOG) to encode an image and to generate a smaller size of the original image [218]. The proposed mechanism locates the area of an image that resembles a generic HOG encoding of a person's face with the help of a reduced version of the image. Secondly, the person's face may not always be straight, and it could be rotated in different positions. There can be some issues, such as brightness, which is solved using a model proposed in literature called named Dlib invigorated with ResNet [219]. The third step refers to object detection using YOLO to increase accuracy because it is challenging to select unique features from a person's face that can be used to differentiate them from other persons. Lastly, machine learning algorithms have been used to find the person's name from the encoded data.

\subsubsection{Temperature Identification System}

This section discusses a body temperature measuring system using an onboardthermal-camera-equipped UAV. The average human body temperature is $37^{\circ} \mathrm{C}$, more than $38^{\circ} \mathrm{C}$ is considered a high temperature; however, throughout the day, the average temperature differs from person to person. If a person's body temperature is unusual, they will be referred for doctor consultation. The temperature identification system consists of two parts: users and the UAVs. In the first part, the system obtains personal information and 6-9 photographs as input from the users. Then, the system converts these images to $128 \times 1$ vectors rather than sending the full image to protect the user's privacy. UAV responsibilities include extraction of all faces with their coordinates and verifying and 
comparing human faces coordinates captured from normal and thermal cameras. If the body temperature is higher than $37^{\circ} \mathrm{C}$, then it takes that person's face and converts it to a 128-dimensional vector and sends it to the central server. The system compares the selected face with the existing database using machine learning algorithms, finds matches, and sends a notification to the suspected person to consult a doctor soon [21].

\subsubsection{Voice-Based Detection}

Voice detection technology is one of the most convenient systems as it may be introduced to recognize potential COVID-19 patients. A voice detection system is used to measure and to choose who is required to be tested throughout these challenging times since there is a lack of testing kits. Mobile application has been introduced based on machine learning algorithms by university students from the DY Patil Institute, Mumbai, India, to detect COVID-19 patients [220]. In the first stage, one has to speak into their mobile; the values of these parameters are then compared with a normal person's voice to confirm if the candidate is infected with COVID-19 or not [221]. It is difficult to measure the performance accuracy of machine learning models to aid the screening of COVID-19 patients rather than detecting them all at once. Research work is required to use machine learning algorithms to appropriately diagnose all possible symptoms of COVID-19.

\subsubsection{Face Mask Detection}

Detecting the face of a person wearing a mask is a very challenging task. The heat discharged from the human body is affected by wearing masks, and many heat sensors are based on the forehead, which is usually visible. An algorithm for differentiating faces with and without masks was presented. The detection of the face with the mask is made using the YOLOv3 model, detecting persons. The model is advanced enough to recognize face-mask mode. The system collects accurate stats such as the number and percentage of persons wearing masks [21].

\subsection{Blockchain Technologies to Mitigate COVID-19 Challenges}

Nowadays, our globe is challenged with the rapid increase in novel coronavirus disease and has created massive suffering. As of 28th June 2021, it had infected more than 180 million people, and almost 4 million individuals died [222]. After its early discovery in Wuhan, China, the novel virus has been spread to 220 countries and territories. The European parliamentary research service recognized blockchain as the various important technology to mitigate COVID-19 challenges [223]. Potential blockchain solutions for the COVID-19 pandemic include medical supply chain management, contact-tracing purposes, and sharing of patient data across heterogeneous systems [224].

Several worldwide techs and research organizations developed applications and platforms based on blockchain to tackle the COVID-19 pandemic, such as securing and sharing COVID-19 data. For example, WHO launched a project named MiPasa based on hyperledger fabric for supporting the collection of COVID-19 associated data. MiPasa provides sharing of data with researchers, public health officials, scientists, and health professionals. It also helps to introduce feasible methods to support pandemic management and manage epidemics [225]. Moreover, Azbeg et al. [226] presented a precise solution for COVID-19 to develop digital passports and track transmission. Blockchain technology has been used to verify the records of COVID-19 testing and tracking transmission. Further, it offers a health application that facilitates the interaction of patients with professionals to recognize symptoms of COVID-19. Doctors can also use the application to keep track of the health status of the patients. 


\subsubsection{Sharing Patient Data}

Nowadays, healthcare sectors digitally store COVID-19 patient data, including doctor prescriptions, diagnostic reports, and personal information. For example, COVID-19 patient data are stored in a centralized database; however, maintaining the privacy of patient information is one of the main issues in such centralized databases, such as unauthorized access to patients' sensitive data [227]; therefore, consortium blockchain and interplanetary file system (IPFS) proposed distributed storage framework for sharing COVID-19 patient's data [228]. Furthermore, the proposed framework makes things easier for authorized users such as healthcare operators. A blockchain-based solution for handling and storing vaccination data and proof of immunity for persons was proposed [229]. The method offers a secure and well-organized way to maintain vaccination records. The solution is based on Ethereum and relies on the idea of smart contracts in blockchain [230].

\subsubsection{Social Distancing}

Social distancing, i.e., avoiding gatherings and keeping social distances, is the understood guideline for prevention from the COVID-19 pandemic. Blockchain-enabled IoMT presents adequate isolation and quarantine solution to monitor social distancing during the growth of the global pandemic [231]. Individuals with wristwatch sensors will be automatically notified when leaving certain defined regions. Moreover, the combination of IoT-based technologies with blockchain maintain and assures data traceability. Tech giants such as Google and Apple provide APIs for software programmers to trace social distancing using their wearable products [232].

\subsubsection{Smart Hospital}

Many hospitals cannot treat other diseases since most of the clinicians are summoned to handle COVID-19 patients. In addition, there is significant pressure on health systems due to the rapid increase in coronavirus patients. Blockchain-enabled IoMT can assuredly handle pandemic situations [231]. Initially, RFID tags and IoMT devices are used to support tracking and controlling the status of health resources such as ambulances, availability of beds in the hospital, and flaws or failures in healthcare devices such as respirators. Furthermore, blockchain-enabled IoMT is used in hospital buildings to facilitate realtime monitoring of temperature and air quality. Blockchain-enabled IoMT also manages actives devices other than passive components such as tags and sensors. For example, robots are active devices responsible for disinfecting health centers, sanitizing hospital wards and public areas. In the literature, blockchain envisioned software embedded multi-swarming UAVs was proposed to minimize human intervention and to handle the COVID-19 situation. These multi-swarming UAVs have key advantages of reliability, high bandwidth, and very-low latency [233].

\subsubsection{Tracing Epidemic Origin}

Tracing the origin of the COVID-19 pandemic is a challenging and important task for future pandemic preparedness and response. The broad adoption of heat sensors and thermal cameras in many public areas such as educational institutes, hospitals, cafes, airports, and malls can notify deteriorating situations quickly. Different transportation hubs, thermal cameras have been used in public places such as airports and railway stations [234]. The thermal cameras have been implemented to detect people with infection of COVID-19 and other symptomatic diseases. The heat sensors and thermal cameras have been connected with blockchain-enabled IoMT for securing data privacy and ensuring data traceability. Moreover, with the rapid increase in DNA, RNA, and other coronavirus tests, these systems can accelerate the detection of infected people. The connectivity of blockchain-enabled IoMT systems can provide extensive data for many healthcare organizations for AI and machine learning based analysis and tracing the epidemic's origin [231]. 


\section{Convergence Challenges and Solutions}

Although machine learning, IoT, and blockchain are very different technologies and different from each other. In literature, many studies present solutions based on their combinations as a remarkable paradigm shift. Blockchain, machine learning provides solutions to the gaps and vulnerabilities of IoT systems [235]. The security concerns are efficiently solved using intelligent IoT where every IoT device is interconnected using the public trustless environment. Moreover, the distributed peer-to-peer nature of blockchain has been used to address the deficiencies of the IoT client-server paradigm. The distributed architecture of blockchain happens to be an essential technology to solve the traditional single-point failure in IoT. A single point of failure in an IoT system may break the whole system, which is detrimental to achieving high reliability and availability in any system [236]; therefore, the peer-to-peer architecture in blockchain technology is a feasible solution to handle the bottleneck and the point of failure in an IoT system $[237,238]$. Additionally, peer-to-peer networks process and store the IoT data securely and efficiently [239]. Machine learning applications in blockchain include smart home gateway [240,241], transactional data systems in edge computing applications [242,243], tracing supply chains [244], and wireless body area network applications [242,245]. Although the convergence of IoT, machine learning, and blockchain can tackle significant weaknesses of IoT solutions, the adoption is still in its infancy, suffering from various challenges; solutions are needed to address these significant challenges. In addition, there is no consent and consensus mechanism for reference paradigm or model specification on the adaptation of blockchain in IoT. This section presents the fundamentals challenges, advancements, and possible solutions to leveraging the convergence of blockchain, machine learning, and IoT.

\subsection{Adaptation Challenges}

The performance of machine learning models relies on the availability and quality of data, information sharing and privacy regulations, and conditions reliant on system infrastructure and interoperability. Usually, even the most essential health framework is required to share data between medical institutes. For example, according to a survey in $2018,41 \%$ of medical institutions in the United States were unable to digitally share observed data to health care firms [246]. Furthermore, the lack of publicly available diverse and comprehensive datasets is a significant need for future research. In situations where training data technically removes parts of the population data, the relevance of the model to larger populations could be discredited. The inconsistent and incomplete labeling of ethnic, demographic, and other racial information may also affect data quality [247-249]. Machine learning algorithms may unexpectedly increase inconsistency by exaggerating the trial of pandemics and improperly notifying resource allocation based upon insufficient or incomplete data instances. Machine learning models also deal with issues at the deployment level. Healthcare technologies and providers must be careful when using algorithms in different settings. Models trained in a particular socio-economic or cultural context system may not offer similar outcomes for populations with different data features. These models must be experienced with analytical estimation when deployed between different conditions and settings that require time, cost, and human resources. The importance of machine learning applications can also limit the approval, adoption, development of these models in a real-world situation. Usually, there is a compromise between the interpretability and complexity of the models being examined essentially in health care organizations, given adequate and ethical implications of determination. A few surveys studies were identified by comparing machine learning with traditional techniques. For example, more simplistic algorithms showed similar or improved estimation while providing the alternative advantage of interpretability; however, highly complicated algorithms are significantly important for several problems, e.g., for tasks such as image classification.

Blockchain technology initially used in cryptocurrencies has been used with IoT for securing systems and IoT applications. Blockchain is a combination of traditional and distributed databases in which data are publicly available for users in the form of an encrypted 
and unchangeable ledger [250]. Unfortunately, the current IoT framework produces massive data that may prevent the network from service quality disruption. Furthermore, the quality-of-service (QoS) is associated with non-functional attributes such as reliability, security, and cost [251]. Some significant challenges of adopting blockchain in IoT are illustrated in the given Figure 9. Privacy is among the significant challenges in blockchain technology since each block is associated with and can access data of another block, so anyone who wants to look on the blockchain can see whole transactions. Traditional IoT data management is at risk as the collected data are cautious and access unauthorized users such as malicious insiders and external hackers-this is why it is challenging to utilize corrupt data. IoT devices must be connected to a high-quality networking resource and computing storage to share IoT data with different stack holders; however, an IoT network has a smaller number of abilities to connect with blockchain to facilitate innovative business opportunities to advance new applications and services in many areas. Blockchain technology needs more power and memory capacity, while IoT devices are developed with less resources, such as less capacity of storage and data-processing [252]. The need for resources for mining blocks on the peer-to-peer blockchain exceeds the abilities of resource-limited IoT devices.

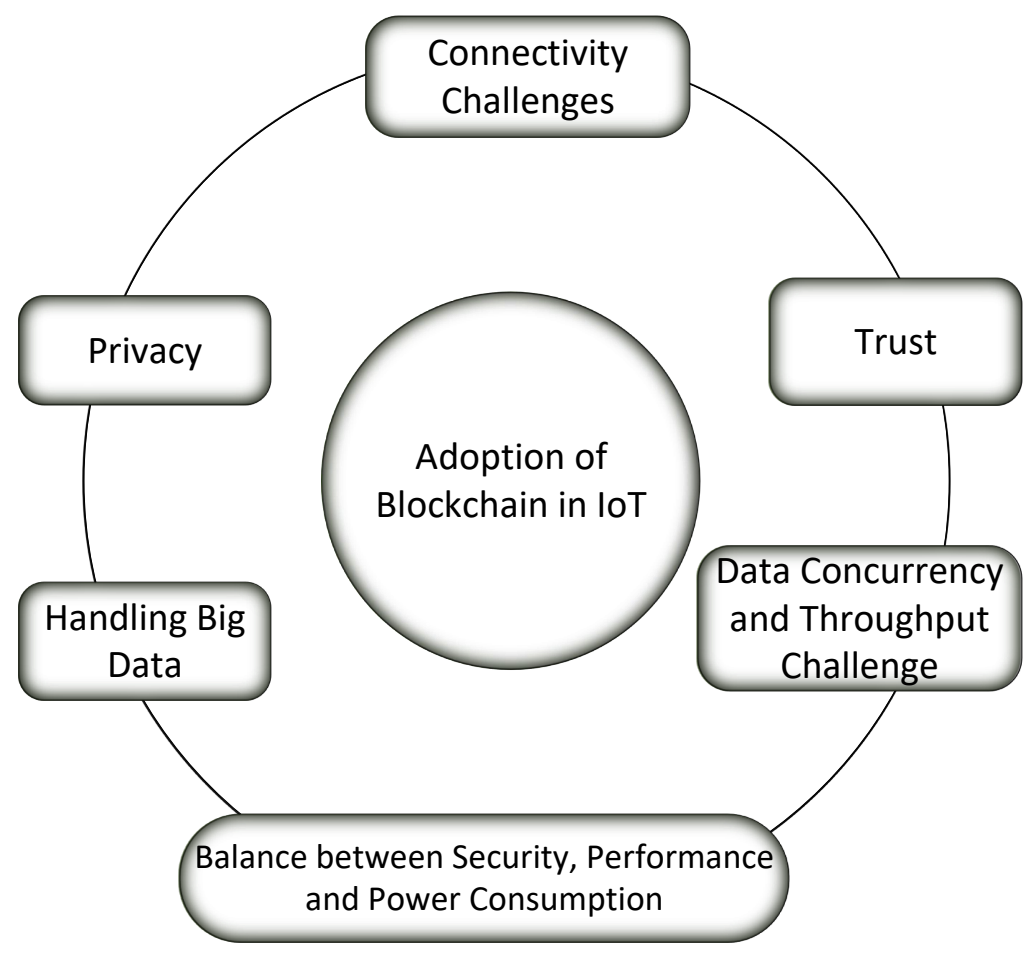

Figure 9. Challenges of adoption of blockchain in IoT.

Furthermore, IoT devices simultaneously generate an immense amount of data, which creates high concurrency. Since the blockchain throughput is restricted due to its security and concurrency processes, quick contemporization of new blocks between nodes requires a high bandwidth speed, hence increasing the blockchain throughput. Despite this, each block contains a replica of the whole distributed ledger. Thus, the distributed storage structure resolves bottleneck issues, enhances efficiency, and eliminates the need for the third party's trust protocols [253]; however, the data management of an IoT system puts overload on the user's private device storage [254]. So, the data storage requirement is a considerable challenge while handling the big data of IoT networks. 


\subsection{Solution of Adaptation Challenges}

Many blockchain features are convenient for diverse IoT applications, such as anonymity, decentralization, immutability, and automation; however, these features integrate several new regulative issues [255]. The immutability feature permanently retains data in distributed ledger technology on the peer-to-peer network and cannot be erased or changed. The data cannot be filtered to maintain privacy before putting them on the blockchain due to a lack of governance. It is not easy to differentiate between groups to perform transactions for unauthorized services because of the anonymity of distributed ledger technology. Actions ensuing from self-executing contracts between two parties, such as smart contracts on distributed ledger technology, can violate the law. The automation feature of the blockchain introduces many advantages to IoT systems. Table 8 shows prospective solutions to the convergence challenges.

Table 8. Convergence challenges and solutions.

\begin{tabular}{|c|c|}
\hline Challenges & Possible Solutions \\
\hline Privacy & $\begin{array}{l}\text { Ring signatures blockchain is an encrypted technology commonly used to handle privacy } \\
\text { issues [256]. Additionally, blockchain-based smart parking with fairness, reliability, and } \\
\text { privacy protection (BSFP) [257] system has been proposed to overcome privacy concerns. } \\
\text { The blockchain-based method exerts group signatures, vector-based encryption, and bloom } \\
\text { filters to protect user's privacy. }\end{array}$ \\
\hline Trust & $\begin{array}{l}\text { This paper [254] presents a blockchain-based decentralized trust management scheme called } \\
\text { BlockBDM to handle the trust and security issues of IoT big data management. Data } \\
\text { processing can be stored in cryptography-signed and tree-based transactions and blocks } \\
\text { with top-quality public and distributed ledger security. }\end{array}$ \\
\hline Connectivity challenges & $\begin{array}{l}\text { For resolving the connectivity issues of an IoT with blockchain, multi-access edge computing } \\
\text { (MEC) [258] can host side-chain. The side-chain allows IoT devices to connect with the main } \\
\text { chain. IoT devices are connected with low bandwidth on the edge network. Side-chain } \\
\text { is a type of blockchain technology that presents a distributed peer-to-peer architecture to } \\
\text { maintain data while sharing critical information between various systems. }\end{array}$ \\
\hline $\begin{array}{l}\text { Balance between security, performance, } \\
\text { and power consumption }\end{array}$ & $\begin{array}{l}\text { These studies }[259,260] \text { proposed a patient-centric agent network to balance between security, } \\
\text { performance, and power consumption which operates on the cloud and edge server and } \\
\text { can manage blockchain actions concerning the IoT devices. Another patient-centric agent } \\
\text { platform in }[260] \text { runs a concurrent tool and handles various blockchains for IoT data. }\end{array}$ \\
\hline $\begin{array}{l}\text { Data concurrency and throughput chal- } \\
\text { lenge }\end{array}$ & $\begin{array}{l}\text { To tackle data concurrency and throughput challenge, researchers presented a method called } \\
\text { sharding [261] in which the peer-to-peer network of blockchain is divided into various } \\
\text { groups. The authentication and processing of transactions are generated in the sharding. } \\
\text { Members of that sharding handle the transactions. Sharding can reduce bandwidth by } \\
\text { preventing the propagation of transactions over the whole system. }\end{array}$ \\
\hline Handling big data & $\begin{array}{l}\text { Many researchers presented off-chain techniques to overcome big data issues in an IoT } \\
\text { system by integrating blockchain storage with standard cloud storage. The alternative } \\
\text { method is used to handling big data challenges is splitting IoT-generated data over dif- } \\
\text { ferent storage's including many on-chain of blockchain-based on the characteristics, local } \\
\text { computers, and cloud service providers [262]. }\end{array}$ \\
\hline
\end{tabular}

Current IoT practices are becoming obsolete with the novel approaches and technologies based on blockchain. These requirements need to be updated according to the latest requirements of distributed ledger technology (DTL). Alternatively, directed acyclic graph (DAG)-based architecture facilitates more advantages than traditional blockchain. Andrew et al. [263] presents a DAG-based distributed ledger based on the Markov chain model to tackle the parasite chain attack. Parasite chain attack aims to obstruct the immutability and irreversibility of the ledger.

\subsection{Future Pandemics Preparedness}

The following section contains a summary of the lessons learned for future pandemic preparedness: Several studies were deeply analyzed from the healthcare domain based on IoT, machine learning, and blockchain applications. For future pandemic preparedness, 
diseases, and global outbreak such as SARS can provide research preparation for techniques that might have allowed advanced governance of the coronavirus outbreak. The coronavirus pandemic's underlying phase investigated machine learning, IoT, and blockchain. Approximately, all this work was at the development and research level, and real-world applications were less common. Developing publicly available immense databases based on clinical information at the domestic or global level would be significantly helpful for researchers. AI-based tools should be developed to enable designing multiple synopses to make better decisions about various options that must be considered, such as the distribution of expensive rare devices and types of equipment such as ventilators, elderly patient monitoring, school, and university education, to name a few.

\subsection{Limitations of the Study}

This comprehensive survey article has many limitations. Most of the research analyzed in this study are applications of IoT and blockchain, machine learning and IoT, and blockchain and machine learning, while unified studies are lacking. Despite the limitations of the existing convergence solutions for IoT, machine learning, and blockchain, several studies have been revealed for future research. This study's main objective was to summarize the critical use cases of IoT, blockchain, and machine learning instead of comprehensively evaluating particular datasets or machine learning algorithms. Our future study will be based on the unified architecture of IoT, machine learning, and blockchain to evaluate convergence inclination and value in experimental conditions. The survey consists of reviews, articles, conference papers to quickly review publications about the coronavirus disease and other future pandemics. The research article survey contained legitimate commercial and business research to discover uses of particular IoT, machine learning, and blockchain applications by governments or organizations to handle coronavirus. Despite the lack of publicly available research resources, this study can be considered a feasible starting point for researchers and commercial firms to understand the background and promising future directions for future pandemics preparation.

\section{Conclusions}

Advancements in IoT communication infrastructure and physical devices have brought immense revolutions in remote health monitoring systems. Machine learning techniques coupled with advanced artificial intelligence techniques detect patterns associated with diseases and health conditions. In this decade, IoT-enabled health monitoring applications have been developed using the integration of blockchain technology with machine learning models to benefit medical report management, drug traceability, and track infectious diseases. To date, contemporary state-of-the-art techniques for the adaptability of blockchain and machine learning in IoT applications are presented. This study presents a comprehensive survey of emerging IoT technologies, machine learning, and blockchain for healthcare applications. The reviewed articles comprise a plethora of research articles published in the web of science in the domain of machine learning, blockchain, and IoT. Firstly, a detailed analysis of healthcare applications of IoT, blockchain, and machine learning demonstrates the importance of the discussed fields. Secondly, the adaptation mechanism of machine learning and blockchain in IoT for healthcare applications are discussed to delineate the scope of the mentioned techniques in IoT domains. Thirdly, leveraging machine learning, blockchain for IoT is discussed from the perspective of pandemic preparation and mitigation. Finally, we discuss challenges in the adaptation of these emerging technologies for IoT-based health care applications. Moreover, a comprehensive summary of several challenges in adapting blockchain in IoT technologies is discussed. The presented future directions in this domain can significantly help the scholarly community to determine research gaps to address. 
Author Contributions: I. conceived the idea for this paper, designed the methodology, and assisted in write-up of the paper. M.I. and U.Z. Write the original article and assisted in the experimental design and paper write-up. J.I., J.G. and M.F. assisted in review and editing. J.G. supervised and proofread this study of Topical Assessment for Pandemic Preparedness, Challenges, and Solutions. All authors have read and agreed to the published version of the manuscript.

Funding: This research received no external funding.

Acknowledgments: This work was supported by the Basic Science Research Program through the National Research Foundation of Korea (NRF) funded by the Ministry of Education (Grant No. NRF-2020R1I1A3074141), the Brain Research Program through the NRF funded by the Ministry of Science, ICT and Future Planning (Grant No. NRF-2019M3C7A1020406), and "Regional Innovation Strategy (RIS)" through the NRF funded by the Ministry of Education.

Conflicts of Interest: The authors declare no conflict of interest.

\section{References}

1. Lv, Z.; Qiao, L.; You, I. 6G-enabled network in box for internet of connected vehicles. IEEE Trans. Intell. Transp. Syst. 2020 22, 5275-5282. [CrossRef]

2. Sestino, A.; Prete, M.I.; Piper, L.; Guido, G. Internet of Things and Big Data as enablers for business digitalization strategies. Technovation 2020, 98, 102173. [CrossRef]

3. Ande, R.; Adebisi, B.; Hammoudeh, M.; Saleem, J. Internet of Things: Evolution and technologies from a security perspective. Sustain. Cities Soc. 2020, 54, 101728. [CrossRef]

4. Granell, C.; Kamilaris, A.; Kotsev, A.; Ostermann, F.O.; Trilles, S. Internet of things. In Manual of Digital Earth; Springer: Singapore, 2020; pp. 387-423.

5. Dong, W.; Li, B.; Guan, G.; Cheng, Z.; Zhang, J.; Gao, Y. TinyLink: A Holistic System for Rapid Development of IoT Applications. ACM Trans. Sens. Netw. (TOSN) 2020, 17, 1-29. [CrossRef]

6. Colakovic, A.; Hadzialic, M. Internet of Things (IoT): A review of enabling technologies, challenges, and open research issues. Comput. Netw. 2018, 144, 17-39. [CrossRef]

7. Iqbal, N.; Ahmad, S.; Ahmad, R.; Kim, D.H. A Scheduling Mechanism Based on Optimization Using IoT-Tasks Orchestration for Efficient Patient Health Monitoring. Sensors 2021, 21, 5430. [CrossRef]

8. Sezer, O.B.; Dogdu, E.; Ozbayoglu, A.M. Context-aware computing, learning, and big data in internet of things: A survey. IEEE Internet Things J. 2017, 5, 1-27. [CrossRef]

9. Reddy, Y.S.; Dubey, A.; Kumar, A.; Panigrahi, T. A Successive Interference Cancellation Based Random Access Channel Mechanism for Machine-to-Machine Communications in Cellular Internet-of-Things. IEEE Access 2021, 9, 8367-8380. [CrossRef]

10. Amato, F.; Moscato, V.; Picariello, A.; Sperlí, G. Kira: A system for knowledge-based access to multimedia art collections. In Proceedings of the 2017 IEEE 11th International Conference on Semantic Computing (ICSC), San Diego, CA, USA, 30 March 2017; pp. 338-343.

11. Singh, S.; Hosen, A.S.; Yoon, B. Blockchain security attacks, challenges, and solutions for the future distributed iot network. IEEE Access 2021, 9, 13938-13959.

12. Faisal, J.; Dohyeun, K. An Ensemble of a Prediction and Learning Mechanism for Improving Accuracy of Anomaly Detection in Network Intrusion Environments. Sustainability 2021, 13, 10057.

13. Hassan, R.J.; Zeebaree, S.R.; Ameen, S.Y.; Kak, S.F.; Sadeeq, M.A.; Ageed, Z.S.; Adel, A.Z.; Salih, A.A. State of art survey for iot effects on smart city technology: Challenges, opportunities, and solutions. Asian J. Res. Comput. Sci. 2021, 32-48. [CrossRef]

14. Ghaffar, Z.; Alshahrani, A.; Fayaz, M.; Alghamdi, A.M.; Gwak, J. A Topical Review on Machine Learning, Software Defined Networking, Internet of Things Applications: Research Limitations and Challenges. Electronics 2021, 10, 880.

15. Stoyanova, M.; Nikoloudakis, Y.; Panagiotakis, S.; Pallis, E.; Markakis, E.K. A survey on the internet of things (IoT) forensics: Challenges, approaches, and open issues. IEEE Commun. Surv. Tutor. 2020, 22, 1191-1221. [CrossRef]

16. Al-Fuqaha, A.; Guizani, M.; Mohammadi, M.; Aledhari, M.; Ayyash, M. Internet of things: A survey on enabling technologies, protocols, and applications. IEEE Commun. Surv. Tutor. 2015, 17, 2347-2376. [CrossRef]

17. Miladinovic, I.; Schefer-Wenzl, S. A highly scalable iot architecture through network function virtualization. Open J. Internet Things (OJIOT) 2017, 3, 127-135.

18. Conti, M.; Dehghantanha, A.; Franke, K.; Watson, S. Internet of Things Security and Forensics: Challenges and Opportunities. Future Gener. Comput. Syst. 2018, 78, 544-546. [CrossRef]

19. Amirinasab Nasab, M.; Shamshirband, S.; Chronopoulos, A.T.; Mosavi, A.; Nabipour, N. Energy-efficient method for wireless sensor networks low-power radio operation in internet of things. Electronics 2020, 9, 320. [CrossRef]

20. Sicari, S.; Rizzardi, A.; Grieco, L.A.; Coen-Porisini, A. Security, privacy and trust in Internet of Things: The road ahead. Comput. Netw. 2015, 76, 146-164. [CrossRef]

21. Barnawi, A.; Chhikara, P.; Tekchandani, R.; Kumar, N.; Alzahrani, B. Artificial intelligence-enabled Internet of Things-based system for COVID-19 screening using aerial thermal imaging. Future Gener. Comput. Syst. 2021, 124, 119-132. [CrossRef] 
22. Tobias, F. Business Model Innovation Based on Software Robotics for Mobile Network Operators. Ph.D. Thesis, University of South Wales, Pontypridd, UK, 2021.

23. Imran; Zaman, U.; Waqar, M.; Zaman, A. Using Machine Learning Algorithms for Housing Price Prediction: The Case of Islamabad Housing Data. Soft Comput. Mach. Intell. J. 2021, 1, 11-23.

24. Naeem, I.; Faisal, J.; Shabir, A.; Dohyeun, K. A novel blockchain-based integrity and reliable veterinary clinic information management system using predictive analytics for provisioning of quality health services. IEEE Access 2021, 9, 8069-8098.

25. Ahmad, S.; Kim, D.H. Quantum GIS based descriptive and predictive data analysis for effective planning of waste management. IEEE Access 2020, 8, 46193-46205.

26. Shabir, A.; Faisal, J.; Naeem, I.; Dohyeun, K. Optimal route recommendation for waste carrier vehicles for efficient waste collection: A step forward towards sustainable cities. IEEE Access 2020, 8, 77875-77887.

27. Ahmad, M.; Alowibdi, J.S.; Ilyas, M.U. vIoT: A first step towards a shared, multi-tenant IoT Infrastructure architecture. In Proceedings of the 2017 IEEE International Conference on Communications Workshops (ICC Workshops), Paris, France, 21-25 May 2017; pp. 308-313.

28. Wahid, F.; Fayaz, M.; Aljarbouh, A.; Mir, M.; Aamir, M. Energy consumption optimization and user comfort maximization in smart buildings using a hybrid of the firefly and genetic algorithms. Energies 2020, 13, 4363. [CrossRef]

29. Cagigas, D.; Clifton, J.; Diaz-Fuentes, D.; Fernández-Gutiérrez, M. Blockchain for Public Services: A Systematic Literature Review. IEEE Access 2021, 9, 13904-13921. [CrossRef]

30. Zheng, W.; Zheng, Z.; Chen, X.; Dai, K.; Li, P.; Chen, R. NutBaaS: A Blockchain-as-a-Service Platform. IEEE Access 2019, 7, 134422-134433. [CrossRef]

31. Monrat, A.A.; Schelén, O.; Andersson, K. A Survey of Blockchain From the Perspectives of Applications, Challenges, and Opportunities. IEEE Access 2019, 7, 117134-117151. [CrossRef]

32. Faisal, J.; Kook, K.H.; Suyeon, K.; Do-Hyeun, K. Towards Secure Fitness Framework Based on IoT-Enabled Blockchain Network Integrated with Machine Learning Algorithms. Sensors 2021, 21, 1640.

33. Faisal, J.; Naeem, I.; Shabir, A.; Dohyeun, K. Peer-to-peer energy trading mechanism based on blockchain and machine learning for sustainable electrical power supply in smart grid. IEEE Access 2021, 9, 39193-39217.

34. Faisal, J.; Faiza, Q.; Soha, A.; Farjeel, J.; Ammar, M. Intelligent Microservice Based on Blockchain for Healthcare Applications. CMC-Comput. Mater. Contin. 2021, 69, 2513-2530.

35. Muzammal, M.; Talat, R.; Sodhro, A.H.; Pirbhulal, S. A multi-sensor data fusion enabled ensemble approach for medical data from body sensor networks. Inf. Fusion 2020, 53, 155-164. [CrossRef]

36. Leminen, S.; Rajahonka, M.; Wendelin, R.; Westerlund, M. Industrial internet of things business models in the machine-to-machine context. Ind. Mark. Manag. 2020, 84, 298-311. [CrossRef]

37. Madakam, S.; Lake, V.; Lake, V.; Lake, V. Internet of Things (IoT): A literature review. J. Comput. Commun. 2015, 3, 164. [CrossRef]

38. Lu, M.; Li, F. Survey on lie group machine learning. Big Data Min. Anal. 2020, 3, 235-258. [CrossRef]

39. Rizwan, A.; Iqbal, N.; Ahmad, R.; Kim, D.H. WR-SVM Model Based on the Margin Radius Approach for Solving the Minimum Enclosing Ball Problem in Support Vector Machine Classification. Appl. Sci. 2021, 11, 4657. [CrossRef]

40. Zheng, Z.; Xie, S.; Dai, H.; Chen, X.; Wang, H. An overview of blockchain technology: Architecture, consensus, and future trends. In Proceedings of the 2017 IEEE International Congress on Big Data (BigData Congress), Honolulu, HI, USA, 25-30 June 2017; pp. 557-564.

41. Chen, M.; Miao, Y.; Humar, I. Background introduction of the internet of things. In OPNET IoT Simulation; Springer: Berlin, Germany, 2019; pp. 1-76.

42. Kim, G.; Kim, J.; Lee, S. An SDN based fully distributed NAT traversal scheme for IoT global connectivity. In Proceedings of the 2015 International Conference on Information and Communication Technology Convergence (ICTC), Jeju Island, Korea, 28-30 October 2015; pp. 807-809.

43. Garg, N.; Wazid, M.; Das, A.K.; Singh, D.P.; Rodrigues, J.J.; Park, Y. BAKMP-IoMT: Design of blockchain enabled authenticated key management protocol for internet of medical things deployment. IEEE Access 2020, 8, 95956-95977. [CrossRef]

44. Ahmad, S.; Kim, D. Design and implementation of thermal comfort system based on tasks allocation mechanism in smart homes. Sustainability 2019, 11, 5849.

45. Ahmad, S.; Kim, D.H. A task orchestration approach for efficient mountain fire detection based on microservice and predictive analysis In IoT environment. J. Intell. Fuzzy Syst. 2021, 40, 5681-5696.

46. Iqbal, N.; Ahmad, S.; Kim, D.H. Health Monitoring System for Elderly Patients Using Intelligent Task Mapping Mechanism in Closed Loop Healthcare Environment. Symmetry 2021, 13, 357.

47. Iqbal, N.; Ahmad, S.; Kim, D.H. Towards mountain fire safety using fire spread predictive analytics and mountain fire containment in iot environment. Sustainability 2021, 13, 2461.

48. Minerva, R.; Biru, A.; Rotondi, D. Towards a definition of the Internet of Things (IoT). IEEE Internet Initiat. $2015,1,1-86$.

49. Park, B.; Kwon, K. 2.4-GHz Bluetooth low energy receiver employing new quadrature low-noise amplifier for low-power low-voltage IoT applications. IEEE Trans. Microw. Theory Technol. 2020, 69, 1887-1895. [CrossRef]

50. Alladi, T.; Chamola, V.; Sikdar, B.; Choo, K.K.R. Consumer IoT: Security vulnerability case studies and solutions. IEEE Consum. Electron. Mag. 2020, 9, 17-25. [CrossRef] 
51. Babun, L.; Aksu, H.; Ryan, L.; Akkaya, K.; Bentley, E.S.; Uluagac, A.S. Z-iot: Passive device-class fingerprinting of zigbee and z-wave iot devices. In Proceedings of the ICC 2020-2020 IEEE International Conference on Communications (ICC), Dublin, Ireland, 7-11 June 2020; pp. 1-7.

52. Krasniqi, Z.; Vershevci, B. Smart Home: Automatic Control Of Lighting Through Z-Wave Iot Technology. In Proceedings of the UBT International Conference, Lipjan, Kosovo, 30-31 November 2020; Volume 31.

53. Fraga-Lamas, P.; Celaya-Echarri, M.; Azpilicueta, L.; Lopez-Iturri, P.; Falcone, F.; Fernández-Caramés, T.M. Design and Empirical Validation of a Lorawan IoT Smart Irrigation System. Proceedings 2020, 42, 62. [CrossRef]

54. Basford, P.J.; Bulot, F.M.; Apetroaie-Cristea, M.; Cox, S.J.; Ossont, S.J. LoRaWAN for smart city IoT deployments: A long term evaluation. Sensors 2020, 20, 648. [CrossRef] [PubMed]

55. Codeluppi, G.; Cilfone, A.; Davoli, L.; Ferrari, G. LoRaFarM: A LoRaWAN-based smart farming modular IoT architecture. Sensors 2020, 20, 2028. [CrossRef] [PubMed]

56. Langley, D.J.; van Doorn, J.; Ng, I.C.; Stieglitz, S.; Lazovik, A.; Boonstra, A. The Internet of Everything: Smart things and their impact on business models. J. Bus. Res. 2021, 122, 853-863. [CrossRef]

57. De Amorim Silva, R.; Braga, R.T.V. Enhancing Future Classroom Environments Based on Systems of Systems and the Internet of Anything. IEEE Internet Things J. 2020, 7, 10475-10482. [CrossRef]

58. Rahman, M.A.; Asyhari, A.T. The Emergence of Internet of Things (IoT): Connecting Anything, Anywhere. Computers 2019, 8, 40. [CrossRef]

59. Chen, S.; Ma, R.; Chen, H.H.; Zhang, H.; Meng, W.; Liu, J. Machine-to-machine communications in ultra-dense networks-A survey. IEEE Commun. Surv. Tutor. 2017, 19, 1478-1503. [CrossRef]

60. Tur, M.R.; Bayindir, R. The Requirements of the Technique of Communication from Machine to Machine Applied in Smart Grids. In Artificial Intelligence and Evolutionary Computations in Engineering Systems; Springer: Berlin, Germany, 2020; pp. 405-418.

61. Pourghebleh, B.; Hayyolalam, V.; Anvigh, A.A. Service discovery in the Internet of Things: Review of current trends and research challenges. Wirel. Netw. 2020, 26, 5371-5391. [CrossRef]

62. Ibrahim, M.; Imran, M.; Jamil, F.; Lee, Y.J.; Kim, D.H. EAMA: Efficient adaptive migration algorithm for cloud data centers (CDCs). Symmetry 2021, 13, 690. [CrossRef]

63. Salam, A. Internet of things for sustainable mining. In Internet of Things for Sustainable Community Development; Springer: Berlin, Germany, 2020; pp. 243-271.

64. Callegati, F.; Cerroni, W.; Contoli, C.; Santandrea, G. Dynamic chaining of virtual network functions in cloud-based edge networks. In Proceedings of the 2015 1st IEEE Conference on Network Softwarization (NetSoft), London, UK, 13-17 April 2015; pp. 1-5.

65. Chowdhury, A.U.; Elahi, M.M. Design of a Smart Gateway for Edge Enabled IoT Applications. In Proceedings of the 2020 IEEE Region 10 Symposium (TENSYMP), Dhaka, Bangladesh, 5-7 June 2020; pp. 417-420.

66. Alhaidari, F.; Rahman, A.; Zagrouba, R. Cloud of Things: Architecture, applications and challenges. J. Ambient. Intell. Humaniz. Comput. 2020, 1-19. [CrossRef]

67. Balasubramanian, S.; Meyyappan, T. Game Theory Based Offload and Migration-Enabled Smart Gateway for Cloud of Things in Fog Computing. In Computing in Engineering and Technology; Springer: Berlin, Germany, 2020; pp. 253-266.

68. Seol, S.; Shin, Y.; Kim, W. Design and realization of personal IoT architecture based on mobile gateway. Int. J. Smart Home 2015, 9, 133-144. [CrossRef]

69. Al Asif, M.R.; Mahfuz, N.; Momin, M.A. An SDN-Enabled IoT Architecture with Fog Computing and Edge Encryption Support. In Proceedings of the International Joint Conference on Computational Intelligence, Dhaka, Bangladesh, 25-26 October 2019; Springer: Berlin, Germany, 2020; pp. 409-423.

70. Atzori, L.; Iera, A.; Morabito, G. Understanding the Internet of Things: Definition, potentials, and societal role of a fast evolving paradigm. Ad Hoc Netw. 2017, 56, 122-140. [CrossRef]

71. Gonçalves, P.; Ferreira, J.; Pedreiras, P.; Corujo, D. Adapting SDN datacenters to support Cloud IIoT applications. In Proceedings of the 2015 IEEE 20th Conference on Emerging Technologies \& Factory Automation (ETFA), Luxembourg, 8-11 September 2015; pp. 1-4.

72. Khan, P.W.; Byun, Y.C.; Park, N. IoT-blockchain enabled optimized provenance system for food industry 4.0 using advanced deep learning. Sensors 2020, 20, 2990. [CrossRef] [PubMed]

73. Khan, P.W.; Byun, Y.C. Secure transactions management using blockchain as a service software for the internet of things. In Software Engineering in IoT, Big Data, Cloud and Mobile Computing; Springer: Berlin, Germany, 2021; pp. 117-128.

74. Sadeghi, A.R.; Wachsmann, C.; Waidner, M. Security and privacy challenges in industrial internet of things. In Proceedings of the 2015 52nd ACM/EDAC/IEEE Design Automation Conference (DAC), San Francisco, CA, USA, 8-12 June 2015; pp. 1-6.

75. Aazam, M.; Zeadally, S.; Harras, K.A. Deploying fog computing in industrial internet of things and industry 4.0. IEEE Trans. Ind. Inform. 2018, 14, 4674-4682. [CrossRef]

76. Espinoza, H.; Kling, G.; McGroarty, F.; O’Mahony, M.; Ziouvelou, X. Estimating the impact of the Internet of Things on productivity in Europe. Heliyon 2020, 6, e03935. [CrossRef]

77. Farris, I.; Girau, R.; Militano, L.; Nitti, M.; Atzori, L.; Iera, A.; Morabito, G. Social virtual objects in the edge cloud. IEEE Cloud Comput. 2015, 2, 20-28. [CrossRef]

78. Mahapatra, T. Composing high-level stream processing pipelines. J. Big Data 2020, 7, 1-28. [CrossRef] 
79. Khomh, F.; Adams, B.; Cheng, J.; Fokaefs, M.; Antoniol, G. Software Engineering for Machine-Learning Applications: The Road Ahead. IEEE Softw. 2018, 35, 81-84. [CrossRef]

80. Khan, A.N.; Iqbal, N.; Ahmad, R.; Kim, D.H. Ensemble prediction approach based on learning to statistical model for efficient building energy consumption management. Symmetry 2021, 13, 405. [CrossRef]

81. Lee, I.; Shin, Y.J. Machine learning for enterprises: Applications, algorithm selection, and challenges. Bus. Horiz. 2020, 63, 157-170. [CrossRef]

82. Mashamba-Thompson, T.P.; Crayton, E.D. Blockchain and Artificial Intelligence Technology for Novel Coronavirus Disease 2019 Self-Testing. Diagnostics 2020, 10, 198. [CrossRef]

83. Ahmad, I.; Shahabuddin, S.; Malik, H.; Harjula, E.; Leppänen, T.; Loven, L.; Anttonen, A.; Sodhro, A.H.; Alam, M.M.; Juntti, M.; et al. Machine learning meets communication networks: Current trends and future challenges. IEEE Access 2020, 8, 223418-223460. [CrossRef]

84. Rahman, A.; Islam, M.J.; Montieri, A.; Nasir, M.K.; Reza, M.M.; Band, S.S.; Pescape, A.; Hasan, M.; Sookhak, M.; Mosavi, A. SmartBlock-SDN: An Optimized Blockchain-SDN Framework for Resource Management in IoT. IEEE Access 2021, 9, 28361-28376. [CrossRef]

85. Gazis, V.; Görtz, M.; Huber, M.; Leonardi, A.; Mathioudakis, K.; Wiesmaier, A.; Zeiger, F.; Vasilomanolakis, E. A survey of technologies for the internet of things. In Proceedings of the 2015 International Wireless Communications and Mobile Computing Conference (IWCMC), Dubrovnik, Croatia, 24-28 August 2015; pp. 1090-1095.

86. Distefano, S.; Merlino, G.; Puliafito, A. A utility paradigm for IoT: The sensing Cloud. Pervasive Mob. Comput. 2015, 20, 127-144. [CrossRef]

87. Czarnecka, P. The Multi-Tenant Cloud Computing Architecture Allows the Service Consumers to Share the Computing. Tenn. Res. Int. Soc. Sci. 2020, 2, 1-21.

88. Datta, S.K.; Bonnet, C.; Haerri, J. Fog computing architecture to enable consumer centric internet of things services. In Proceedings of the 2015 International Symposium on Consumer Electronics (ISCE), Madrid, Spain, 24-26 June 2015; pp. 1-2.

89. Sandor, H.; Genge, B.; Sebestyen-Pal, G. Resilience in the Internet of Things: The software defined networking approach. In Proceedings of the 2015 IEEE International Conference on Intelligent Computer Communication and Processing (ICCP), Cluj-Napoca, Romania, 3-5 September 2015; pp. 545-552.

90. Magsi, H.; Sodhro, A.H.; Zahid, N.; Pirbhulal, S.; Wang, L.; Al-Rakhami, M.S. A Novel Adaptive Battery-Aware Algorithm for Data Transmission in IoT-Based Healthcare Applications. Electronics 2021, 10, 367. [CrossRef]

91. Lakhan, A.; Dootio, M.A.; Groenli, T.M.; Sodhro, A.H.; Khokhar, M.S. Multi-layer latency aware workload assignment of e-transport iot applications in mobile sensors cloudlet cloud networks. Electronics 2021, 10, 1719. [CrossRef]

92. Klingeberg, T.; Schilling, M. Mobile wearable device for long term monitoring of vital signs. Comput. Methods Programs Biomed. 2012, 106, 89-96. [CrossRef]

93. Vedaei, S.S.; Fotovvat, A.; Mohebbian, M.R.; Rahman, G.M.E.; Wahid, K.A.; Babyn, P.; Marateb, H.R.; Mansourian, M.; Sami, R. COVID-SAFE: An IoT-Based System for Automated Health Monitoring and Surveillance in Post-Pandemic Life. IEEE Access 2020, 8, 188538-188551. [CrossRef]

94. Xu, G. IoT-Assisted ECG Monitoring Framework With Secure Data Transmission for Health Care Applications. IEEE Access 2020, 8, 74586-74594. [CrossRef]

95. Zheng, M.; Bai, S. Implementation of Universal Health Management and Monitoring System in Resource-Constrained Environment Based on Internet of Things. IEEE Access 2021. [CrossRef]

96. Singh, P.; Raw, R.S.; Khan, S.A.; Mohammed, M.A.; Aly, A.A.; Le, D.N. W-GeoR: Weighted Geographical Routing for VANET's Health Monitoring Applications in Urban Traffic Networks. IEEE Access 2021. [CrossRef]

97. Pathinarupothi, R.K.; Durga, P.; Rangan, E.S. IoT-Based Smart Edge for Global Health: Remote Monitoring With Severity Detection and Alerts Transmission. IEEE Internet Things J. 2019, 6, 2449-2462. [CrossRef]

98. Zhou, Z.; Yu, H.; Shi, H. Human Activity Recognition Based on Improved Bayesian Convolution Network to Analyze Health Care Data Using Wearable IoT Device. IEEE Access 2020, 8, 86411-86418. [CrossRef]

99. Al Disi, M.; Djelouat, H.; Kotroni, C.; Politis, E.; Amira, A.; Bensaali, F.; Dimitrakopoulos, G.; Alinier, G. ECG Signal Reconstruction on the IoT-Gateway and Efficacy of Compressive Sensing Under Real-Time Constraints. IEEE Access 2018, 6, 69130-69140. [CrossRef]

100. Bacco, M.; Barsocchi, P.; Cassará, P.; Germanese, D.; Gotta, A.; Leone, G.R.; Moroni, D.; Pascali, M.A.; Tampucci, M. Monitoring Ancient Buildings: Real Deployment of an IoT System Enhanced by UAVs and Virtual Reality. IEEE Access 2020, 8, 50131-50148. [CrossRef]

101. Ghosh, A.M.; Halder, D.; Hossain, S.K.A. Remote health monitoring system through IoT. In Proceedings of the 2016 th International Conference on Informatics, Electronics and Vision (ICIEV), Dhaka, Bangladesh, 13-14 May 2016; pp. 921-926. [CrossRef]

102. Cheikhrouhou, O.; Mahmud, R.; Zouari, R.; Ibrahim, M.; Zaguia, A.; Gia, T.N. One-dimensional CNN approach for ECG arrhythmia analysis in fog-cloud environments. IEEE Access 2021, 9, 103513-103523. [CrossRef]

103. Abtahi, F.; Aslamy, B.; Boujabir, I.; Seoane, F.; Lindecrantz, K. An affordable ECG and respiration monitoring system based on Raspberry PI and ADAS1000: First step towards homecare applications. In Proceedings of the 16th Nordic-Baltic Conference on Biomedical Engineering, Gothenburg, Sweden, 14-16 October 2014; Springer: Berlin, Germany, 2014; pp. 5-8. 
104. Jamil, H.H.; Qayyum, F.; Jamil, F.; Kim, D.-H. Enhanced PDR-BLE Compensation Mechanism Based on HMM and AWCLA for Improving Indoor Localization. Sensors 2021, 1, 1.

105. Moghadas, E.; Rezazadeh, J.; Farahbakhsh, R. An IoT patient monitoring based on fog computing and data mining: Cardiac arrhythmia usecase. Internet Things 2020, 11, 100251. [CrossRef]

106. Helmy, J.; Helmy, A. The Alzimio App for Dementia, Autism Alzheimer's: Using Novel Activity Recognition Algorithms and Geofencing. In Proceedings of the 2016 IEEE International Conference on Smart Computing (SMARTCOMP), Shenzhen, China, 17-19 December 2016; pp. 1-6. [CrossRef]

107. Patii, N.; Iyer, B. Health monitoring and tracking system for soldiers using Internet of Things(IoT). In Proceedings of the 2017 International Conference on Computing, Communication and Automation (ICCCA), Greater Noida, India, 5-6 May 2017; pp. 1347-1352. [CrossRef]

108. Sobin, C. A survey on architecture, protocols and challenges in IoT. Wirel. Pers. Commun. 2020, 112, 1383-1429. [CrossRef]

109. Jebadurai, J.; Peter, J.D. Super-resolution of retinal images using multi-kernel SVR for IoT healthcare applications. Future Gener. Comput. Syst. 2018, 83, 338-346. [CrossRef]

110. Chuang, J.; Maimoon, L.; Yu, S.; Zhu, H.; Nybroe, C.; Hsiao, O.; Li, S.H.; Lu, H.; Chen, H. SilverLink: Smart home health monitoring for senior care. In ICSH; Springer: Berlin, Germany, 2015; pp. 3-14.

111. Namahoot, C.S.; Brückner, M.; Nuntawong, C. Mobile diagnosis system with emergency telecare in Thailand (MOD-SET). Procedia Comput. Sci. 2015, 69, 86-95. [CrossRef]

112. Korzun, D.G.; Borodin, A.V.; Timofeev, I.A.; Paramonov, I.V.; Balandin, S.I. Digital assistance services for emergency situations in personalized mobile healthcare: Smart space based approach. In Proceedings of the 2015 International Conference on Biomedical Engineering and Computational Technologies (SIBIRCON), Novosibirsk, Russia, 28-30 October 2015; pp. $62-67$.

113. Ahmad, N.; Han, L.; Iqbal, K.; Ahmad, R.; Abid, M.A.; Iqbal, N. SARM: Salah activities recognition model based on smartphone. Electronics 2019, 8, 881. [CrossRef]

114. Pace, P.; Gravina, R.; Aloi, G.; Fortino, G.; Ibanez-Sanchez, G.; Traver, V.; Palau, C.; Yacchirema, D. IoT platforms interoperability for active and assisted living healthcare services support. In Proceedings of the 2017 Global Internet of Things Summit (GIoTS), Geneva, Switzerland, 6-9 June 2017; pp. 1-6.

115. Bisio, I.; Lavagetto, F.; Marchese, M.; Sciarrone, A. A smartphone-centric platform for remote health monitoring of heart failure. Int. J. Commun. Syst. 2015, 28, 1753-1771. [CrossRef]

116. Basanta, H.; Huang, Y.P.; Lee, T.T. Intuitive IoT-based H2U healthcare system for elderly people. In Proceedings of the 2016 IEEE 13th International Conference on Networking, Sensing, and Control (ICNSC), Mexico City, Mexico, 28-30 April 2015; pp. 1-6.

117. Yogaraj, A.; Ezilarasan, M.; Anuroop, R.; Sivanthiram, C.; Thakur, S.K. IOT based smart healthcare monitoring system for rural/isolated areas. Int. J. Pure Appl. Math. 2017, 114, 679-688.

118. Khachane, J.L.; Desai, L.R. ECG Web Services for Patient Health Monitoring in Internet of Things. Int. J. Comput. Appl. 2016, 148, 26-30.

119. Kumar, R.; Rajasekaran, M.P. An IoT based patient monitoring system using raspberry Pi. In Proceedings of the 2016 International Conference on Computing Technologies and Intelligent Data Engineering (ICCTIDE'16), Kovilpatti, India, 7-9 January 2016; pp. 1-4.

120. Yang, Z.; Zhou, Q.; Lei, L.; Zheng, K.; Xiang, W. An IoT cloud based wearable ECG monitoring system for smart healthcare. J. Med. Syst. 2016, 40, 1-11. [CrossRef]

121. Garg, L.; Chukwu, E.; Nasser, N.; Chakraborty, C.; Garg, G. Anonymity preserving IoT-based COVID-19 and other infectious disease contact tracing model. IEEE Access 2020, 8, 159402-159414. [CrossRef]

122. Apratim, H.; Raj, A.; Roy, A.B. NFC based Public Healthcare Monitoring System. Int. J. Adv. Res. Electron. Commun. Eng. (IJARECE) 2015, 4, 212-217.

123. Wiens, J.; Saria, S.; Sendak, M.; Ghassemi, M.; Liu, V.X.; Doshi-Velez, F.; Jung, K.; Heller, K.; Kale, D.; Saeed, M.; et al. Do no harm: A roadmap for responsible machine learning for health care. Nat. Med. 2019, 25, 1337-1340. [CrossRef] [PubMed]

124. Huang, L.; Wang, L.; Hu, X.; Chen, S.; Tao, Y.; Su, H.; Yang, J.; Xu, W.; Vedarethinam, V.; Wu, S.; et al. Machine learning of serum metabolic patterns encodes early-stage lung adenocarcinoma. Nat. Commun. 2020, 11, 1-11. [CrossRef]

125. Magna, A.A.R.; Allende-Cid, H.; Taramasco, C.; Becerra, C.; Figueroa, R.L. Application of Machine Learning and Word Embeddings in the Classification of Cancer Diagnosis Using Patient Anamnesis. IEEE Access 2020, 8, 106198-106213. [CrossRef]

126. Shailaja, K.; Seetharamulu, B.; Jabbar, M.A. Machine Learning in Healthcare: A Review. In Proceedings of the 2018 Second International Conference on Electronics, Communication and Aerospace Technology (ICECA), Coimbatore, India, 29-31 March 2018; pp. 910-914. [CrossRef]

127. Norgeot, B.; Glicksberg, B.S.; Butte, A.J. A call for deep-learning healthcare. Nat. Med. 2019, 25, 14-15. [CrossRef]

128. Vembandasamy, K.; Sasipriya, R.; Deepa, E. Heart diseases detection using Naive Bayes algorithm. Int. J. Innov. Sci. Eng. Technol. 2015, 2, 441-444.

129. Qomariah, D.U.N.; Tjandrasa, H.; Fatichah, C. Classification of diabetic retinopathy and normal retinal images using CNN and SVM. In Proceedings of the 2019 12th International Conference on Information \& Communication Technology and System (ICTS), Surabaya, Indonesia, 18 July 2019; pp. 152-157.

130. Shankar, K.; Lakshmanaprabu, S.; Gupta, D.; Maseleno, A.; De Albuquerque, V.H.C. Optimal feature-based multi-kernel SVM approach for thyroid disease classification. J. Supercomput. 2020, 76, 1128-1143. [CrossRef] 
131. Bharat, A.; Pooja, N.; Reddy, R.A. Using machine learning algorithms for breast cancer risk prediction and diagnosis. In Proceedings of the 2018 3rd International Conference on Circuits, Control, Communication and Computing (I4C), Bangalore, India, 3-5 October 2018; pp. 1-4.

132. Sivakami, K.; Saraswathi, N. Mining big data: Breast cancer prediction using DT-SVM hybrid model. Int. J. Sci. Eng. Appl. Sci. (IJSEAS) 2015, 1, 418-429.

133. Tigga, N.P.; Garg, S. Prediction of type 2 diabetes using machine learning classification methods. Procedia Comput. Sci. 2020, 167, 706-716. [CrossRef]

134. Ortega, J.H.J.C.; Resureccion, M.R.; Natividad, L.R.Q.; Bantug, E.T.; Lagman, A.C.; Lopez, S.R. An analysis of classification of breast cancer dataset using J48 algorithm. Int. J. Adv. Trends Comput. Sci. Eng. 2020, 9, 475-480. [CrossRef]

135. Venkatesan, E.; Velmurugan, T. Performance analysis of decision tree algorithms for breast cancer classification. Indian J. Sci. Technol. 2015, 8, 1-8. [CrossRef]

136. Eljamassi, D.F.; Maghari, A.Y. COVID-19 Detection from Chest X-ray Scans using Machine Learning. In Proceedings of the 2020 International Conference on Promising Electronic Technologies (ICPET), Jerusalem, Palestine, 16-17 December 2020; pp. 1-4.

137. Santoso, L.F.; Baqai, F.; Gwozdz, M.; Lange, J.; Rosenberger, M.G.; Sulzer, J.; Paydarfar, D. Applying Machine Learning Algorithms for Automatic Detection of Swallowing from Sound. In Proceedings of the 2019 41st Annual International Conference of the IEEE Engineering in Medicine and Biology Society (EMBC), Berlin, Germany, 23-27 July 2019; pp. 2584-2588.

138. Amirgaliyev, Y.; Shamiluulu, S.; Serek, A. Analysis of chronic kidney disease dataset by applying machine learning methods. In Proceedings of the 2018 IEEE 12th International Conference on Application of Information and Communication Technologies (AICT), Almaty, Kazakhstan, 17-19 October 2018; pp. 1-4.

139. Bhaskar, N.; Manikandan, S. A deep-learning-based system for automated sensing of chronic kidney disease. IEEE Sens. Lett. 2019, 3, 1-4. [CrossRef]

140. Qin, J.; Chen, L.; Liu, Y.; Liu, C.; Feng, C.; Chen, B. A machine learning methodology for diagnosing chronic kidney disease. IEEE Access 2019, 8, 20991-21002. [CrossRef]

141. Lodha, P.; Talele, A.; Degaonkar, K. Diagnosis of alzheimer's disease using machine learning. In Proceedings of the 2018 Fourth International Conference on Computing Communication Control and Automation (ICCUBEA), Pune, India, 16-18 August 2018; pp. 1-4.

142. Nahiduzzaman, M.; Nayeem, M.J.; Ahmed, M.T.; Zaman, M.S.U. Prediction of heart disease using multi-layer perceptron neural network and support vector machine. In Proceedings of the 2019 4th International Conference on Electrical Information and Communication Technology (EICT), Khulna, Bangladesh, 20-22 December 2019; pp. 1-6.

143. Iyer, A.; Jeyalatha, S.; Sumbaly, R. Diagnosis of diabetes using classification mining techniques. arXiv 2015, arXiv:1502.03774.

144. Begum, A.; Parkavi, A. Prediction of thyroid disease using data mining techniques. In Proceedings of the 20195 th International Conference on Advanced Computing \& Communication Systems (ICACCS), Coimbatore, India, 15-16 March 2019; pp. 342-345.

145. Sun, L. Service Chaining Security Based on Blockchain. In Journal of Physics: Conference Series; IOP Publishing: Bristol, UK, 2020; Volume 1634, p. 012031.

146. Nguyen, D.C.; Ding, M.; Pathirana, P.N.; Seneviratne, A. Blockchain and AI-based solutions to combat coronavirus (COVID-19)like epidemics: A survey. IEEE Access 2021, 9, 95730-95753. [CrossRef]

147. Kamath, R. Food traceability on blockchain: Walmart's pork and mango pilots with IBM. J. Br. Blockchain Assoc. $2018,1,3712$. [CrossRef]

148. Ramachandran, A.; Kantarcioglu, M. Smartprovenance: A distributed, blockchain based dataprovenance system. In Proceedings of the Eighth ACM Conference on Data and Application Security and Privacy, Tempe, AZ, USA, 19-21 March 2018 ; pp. 35-42.

149. Tanwar, S.; Parekh, K.; Evans, R. Blockchain-based electronic healthcare record system for healthcare 4.0 applications. J. Inf. Secur. Appl. 2020, 50, 102407. [CrossRef]

150. Liu, X.; Ma, W.; Cao, H. MBPA: A medibchain-based privacy-preserving mutual authentication in TMIS for mobile medical cloud architecture. IEEE Access 2019, 7, 149282-149298. [CrossRef]

151. Daraghmi, E.Y.; Daraghmi, Y.A.; Yuan, S.M. MedChain: A design of blockchain-based system for medical records access and permissions management. IEEE Access 2019, 7, 164595-164613. [CrossRef]

152. Seliem, M.; Elgazzar, K. BIoMT: Blockchain for the internet of medical things. In Proceedings of the 2019 IEEE International Black Sea Conference on Communications and Networking (BlackSeaCom), Sochi, Russia, 3-6 June 2019; pp. 1-4.

153. Kuo, T.T.; Kim, H.E.; Ohno-Machado, L. Blockchain distributed ledger technologies for biomedical and health care applications. J. Am. Med. Inform. Assoc. 2017, 24, 1211-1220. [CrossRef]

154. Gordon, W.J.; Catalini, C. Blockchain technology for healthcare: Facilitating the transition to patient-driven interoperability. Comput. Struct. Biotechnol. J. 2018, 16, 224-230. [CrossRef]

155. Dubovitskaya, A.; Xu, Z.; Ryu, S.; Schumacher, M.; Wang, F. Secure and trustable electronic medical records sharing using blockchain. In Proceedings of the AMIA Annual Symposium Proceedings, Washington, DC, USA, 4-8 November 2017; Volume 2017, p. 650.

156. Ichikawa, D.; Kashiyama, M.; Ueno, T. Tamper-resistant mobile health using blockchain technology. JMIR $m$ Health $u$ Health 2017, 5, e7938. [CrossRef] [PubMed]

157. Patel, V. A framework for secure and decentralized sharing of medical imaging data via blockchain consensus. Health Inform. J. 2019, 25, 1398-1411. [CrossRef] [PubMed] 
158. Tseng, J.H.; Liao, Y.C.; Chong, B.; Liao, S.W. Governance on the drug supply chain via gcoin blockchain. Int. J. Environ. Res. Public Health 2018, 15, 1055. [CrossRef] [PubMed]

159. Griggs, K.N.; Ossipova, O.; Kohlios, C.P.; Baccarini, A.N.; Howson, E.A.; Hayajneh, T. Healthcare blockchain system using smart contracts for secure automated remote patient monitoring. J. Med. Syst. 2018, 42, 1-7. [CrossRef]

160. Roehrs, A.; Da Costa, C.A.; da Rosa Righi, R. OmniPHR: A distributed architecture model to integrate personal health records. J. Biomed. Inform. 2017, 71, 70-81. [CrossRef]

161. Azaria, A.; Ekblaw, A.; Vieira, T.; Lippman, A. Medrec: Using blockchain for medical data access and permission management. In Proceedings of the 2016 2nd International Conference on Open and Big Data (OBD), Vienna, Austria, 22-24 August 2016; pp. $25-30$.

162. Liang, X.; Zhao, J.; Shetty, S.; Liu, J.; Li, D. Integrating blockchain for data sharing and collaboration in mobile healthcare applications. In Proceedings of the 2017 IEEE 28th Annual International Symposium on Personal, Indoor, and Mobile Radio Communications (PIMRC), Montreal, QC, Canada, 8-13 October 2017; pp. 1-5.

163. Bocek, T.; Rodrigues, B.B.; Strasser, T.; Stiller, B. Blockchains everywhere-A use-case of blockchains in the pharma supply-chain. In Proceedings of the 2017 IFIP/IEEE Symposium on Integrated Network and Service Management (IM), Lisbon, Portugal, 8-12 May 2017; pp. 772-777.

164. Huang, Y.; Wu, J.; Long, C. Drugledger: A practical blockchain system for drug traceability and regulation. In Proceedings of the 2018 IEEE International Conference on Internet of Things (iThings) and IEEE Green Computing and Communications (GreenCom) and IEEE Cyber, Physical and Social Computing (CPSCom) and IEEE Smart Data (SmartData), Halifax, NS, Canada, 30 July-3 August 2018; pp. 1137-1144.

165. Twhitelaw, S.; Mamas, M.A.; Topol, E.; Van Spall, H.G. Applications of digital technology in COVID-19 pandemic planning and response. Lancet Digit. Health 2020, 2, e435-e440. [CrossRef]

166. Koshti, M.; Ganorkar, S.; Chiari, L. IoT based health monitoring system by using Raspberry Pi and ECG signal. Int. J. Innov. Res. Sci. Eng. Technol. 2016, 5, 8977-8985.

167. Ting, D.S.W.; Carin, L.; Dzau, V.; Wong, T.Y. Digital technology and COVID-19. Nat. Med. 2020, 26, 459-461. [CrossRef]

168. Kumar, R.; Khan, A.A.; Kumar, J.; Zakria, A.; Golilarz, N.A.; Zhang, S.; Ting, Y.; Zheng, C.; Wang, W. Blockchain-FederatedLearning and Deep Learning Models for COVID-19 detection using CT Imaging. IEEE Sens. J. 2021. [CrossRef]

169. Islam, M.Z.; Zahan, M.K.E.; Al-Bari, M.A.A. Convergence between global BCG vaccination and COVID-19 pandemic. J. Med. Virol. 2021, 93, 1496-1505. [CrossRef] [PubMed]

170. Sapkal, S.A.; Arora, S. Research Issues in IoT. In Computing Technologies and Applications: Paving Path towards Society 5.0; Chapman and Hall: London, UK, 2021; p. 93.

171. Lee, S.M.; Trimi, S. Convergence innovation in the digital age and in the COVID-19 pandemic crisis. J. Bus. Res. 2021, 123, 14-22. [CrossRef]

172. Velavan, T.P.; Meyer, C.G. The COVID-19 epidemic. Trop. Med. Int. Health 2020, 25, 278. [CrossRef]

173. Guan, W.J.; Ni, Z.Y.; Hu, Y.; Liang, W.H.; Ou, C.Q.; He, J.X.; Liu, L.; Shan, H.; Lei, C.L.; Hui, D.S.; et al. Clinical characteristics of 2019 novel coronavirus infection in China. MedRxiv 2020. [CrossRef]

174. Li, Z.; Tomlinson, A.C.; Wong, A.H.; Zhou, D.; Desforges, M.; Talbot, P.J.; Benlekbir, S.; Rubinstein, J.L.; Rini, J.M. The human coronavirus HCoV-229E S-protein structure and receptor binding. Elife 2019, 8, e51230. [CrossRef]

175. Yamaya, M.; Nishimura, H.; Deng, X.; Sugawara, M.; Watanabe, O.; Nomura, K.; Shimotai, Y.; Momma, H.; Ichinose, M.; Kawase, T. Inhibitory effects of glycopyrronium, formoterol, and budesonide on coronavirus HCoV-229E replication and cytokine production by primary cultures of human nasal and tracheal epithelial cells. Respir. Investig. 2020, 58, 155-168. [CrossRef]

176. Ma, Q.; Li, R.; Pan, W.; Huang, W.; Liu, B.; Xie, Y.; Wang, Z.; Li, C.; Jiang, H.; Huang, J.; et al. Phillyrin (KD-1) exerts anti-viral and anti-inflammatory activities against novel coronavirus (SARS-CoV-2) and human coronavirus 229E (HCoV-229E) by suppressing the nuclear factor kappa B (NF- $\kappa$ B) signaling pathway. Phytomedicine 2020, 78, 153296. [CrossRef]

177. Friedman, N.; Alter, H.; Hindiyeh, M.; Mendelson, E.; Shemer Avni, Y.; Mandelboim, M. Human coronavirus infections in Israel: Epidemiology, clinical symptoms and summer seasonality of HCoV-HKU1. Viruses 2018, 10, 515. [CrossRef]

178. Georgakopoulou, V.E.; Petsinis, G.; Mantzouranis, K.; Damaskos, C.; Melemeni, D.; Gkoufa, A.; Chlapoutakis, S.; Garmpis, N.; Sklapani, P.; Trakas, N.; et al. First Detection of Human Coronavirus HKU1 in Greece, in an Immunocompromised Patient With Severe Lower Respiratory Tract Infection. Acta Med. Litu. 2021, 28, 21.

179. Dugas, M.; Grote-Westrick, T.; Vollenberg, R.; Lorentzen, E.; Brix, T.; Schmidt, H.; Tepasse, P.R.; Kühn, J. Less severe course of COVID-19 is associated with elevated levels of antibodies against seasonal human coronaviruses OC43 and HKU1 (HCoV OC43, HCoV HKU1). Int. J. Infect. Dis. 2021, 105, 304-306. [CrossRef] [PubMed]

180. Stone, N.E.; Jaramillo, S.A.; Jones, A.N.; Vazquez, A.J.; Martz, M.; Versluis, L.M.; Raniere, M.O.; Nunnally, H.E.; Zarn, K.E.; Nottingham, R.; et al. Stenoparib, an inhibitor of cellular poly (Adp-ribose) polymerase, blocks replication of the sars-cov-2 and hcov-nl63 human coronaviruses in vitro. Mbio 2021, 12, e03495-20. [CrossRef] [PubMed]

181. Bačenková, D.; Trebuňová, M.; Špakovská, T.; Schnitzer, M.; Bednarčíková, L.; Živčák, J. Comparison of Selected Characteristics of SARS-CoV-2, SARS-CoV, and HCoV-NL63. Appl. Sci. 2021, 11, 1497. [CrossRef]

182. Sanchez-Nadales, A.; Treminio-Quezada, M.; Abad, H.; Navarro-Motta, J.; Contreras-Chavez, P.; Kachru, A.; Chu, C. Critical care management for novel 2019 SARS-CoV-2 and HCoV-NL63 coinfection in a young immunocompromised patient: A Chicago experience. Case Rep. Crit. Care 2020, 2020, 8877641. [CrossRef] 
183. Niu, J.; Shen, L.; Huang, B.; Ye, F.; Zhao, L.; Wang, H.; Deng, Y.; Tan, W. Non-invasive bioluminescence imaging of HCoV-OC43 infection and therapy in the central nervous system of live mice. Antivir. Res. 2020, 173, 104646. [CrossRef]

184. Zhang, S.F.; Tuo, J.L.; Huang, X.B.; Zhu, X.; Zhang, D.M.; Zhou, K.; Yuan, L.; Luo, H.J.; Zheng, B.J.; Yuen, K.Y.; et al. Epidemiology characteristics of human coronaviruses in patients with respiratory infection symptoms and phylogenetic analysis of $\mathrm{HCoV}-\mathrm{OC} 43$ during 2010-2015 in Guangzhou. PLoS ONE 2018, 13, e0191789. [CrossRef] [PubMed]

185. Patrono, L.V.; Samuni, L.; Corman, V.M.; Nourifar, L.; Röthemeier, C.; Wittig, R.M.; Drosten, C.; Calvignac-Spencer, S.; Leendertz, F.H. Human coronavirus OC43 outbreak in wild chimpanzees, Cote d Ivoire, 2016. Emerg. Microbes Infect. 2018, 7, 1-4. [CrossRef] [PubMed]

186. Oboho, I.K.; Tomczyk, S.M.; Al-Asmari, A.M.; Banjar, A.A.; Al-Mugti, H.; Aloraini, M.S.; Alkhaldi, K.Z.; Almohammadi, E.L.; Alraddadi, B.M.; Gerber, S.I.; et al. 2014 MERS-CoV outbreak in Jeddah-A link to health care facilities. N. Engl. J. Med. 2015, 372, 846-854. [CrossRef] [PubMed]

187. Giannis, D.; Ziogas, I.A.; Gianni, P. Coagulation disorders in coronavirus infected patients: COVID-19, SARS-CoV-1, MERS-CoV and lessons from the past. J. Clin. Virol. 2020, 127, 104362. [CrossRef]

188. Van Doremalen, N.; Bushmaker, T.; Morris, D.H.; Holbrook, M.G.; Gamble, A.; Williamson, B.N.; Tamin, A.; Harcourt, J.L.; Thornburg, N.J.; Gerber, S.I.; et al. Aerosol and surface stability of SARS-CoV-2 as compared with SARS-CoV-1. N. Engl. J. Med. 2020, 382, 1564-1567. [CrossRef]

189. Marchand-Senécal, X.; Kozak, R.; Mubareka, S.; Salt, N.; Gubbay, J.B.; Eshaghi, A.; Allen, V.; Li, Y.; Bastien, N.; Gilmour, M.; et al. Diagnosis and management of first case of COVID-19 in Canada: Lessons applied from SARS-CoV-1. Clin. Infect. Dis. 2020, 71, 2207-2210. [CrossRef]

190. Derraik, J.G.; Anderson, W.A.; Connelly, E.A.; Anderson, Y.C. Rapid review of SARS-CoV-1 and SARS-CoV-2 viability, susceptibility to treatment, and the disinfection and reuse of PPE, particularly filtering facepiece respirators. Int. J. Environ. Res. Public Health 2020, 17, 6117. [CrossRef]

191. Fauci, A.S.; Lane, H.C.; Redfield, R.R. COVID-19—Navigating the Uncharted; Massachusetts Medical Society: Waltham, MA, USA, 2020.

192. Kim, D.; Lee, J.Y.; Yang, J.S.; Kim, J.W.; Kim, V.N.; Chang, H. The architecture of SARS-CoV-2 transcriptome. Cell 2020, 181, 914-921. [CrossRef]

193. Lütje, S.; Marinova, M.; Kütting, D.; Attenberger, U.; Essler, M.; Bundschuh, R.A. Nuclear medicine in SARS-CoV-2 pandemia: 18F-FDG-PET/CT to visualize COVID-19. Nuklearmedizin 2020, 59, 276-280. [CrossRef] [PubMed]

194. Hasöksüz, M.; Kiliç, S.; Saraç, F. Coronaviruses and sars-cov-2. Turk. J. Med. Sci. 2020, 50, 549-556. [CrossRef] [PubMed]

195. Pitlik, S.D. COVID-19 compared to other pandemic diseases. Rambam Maimonides Med. J. 2020, 11, e0027. [CrossRef]

196. Otoom, M.; Otoum, N.; Alzubaidi, M.A.; Etoom, Y.; Banihani, R. An IoT-based framework for early identification and monitoring of COVID-19 cases. Biomed. Signal Process. Control 2020, 62, 102149. [CrossRef]

197. Elagan, S.; Abdelwahab, S.F.; Zanaty, E.; Alkinani, M.H.; Alotaibi, H.; Zanaty, M.E. Remote diagnostic and detection of coronavirus disease (COVID-19) system based on intelligent healthcare and internet of things. Results Phys. 2021, 22, 103910. [CrossRef]

198. Chamberlain, S.D.; Singh, I.; Ariza, C.A.; Daitch, A.L.; Philips, P.B.; Dalziel, B.D. Real-time detection of COVID-19 epicenters within the United States using a network of smart thermometers. MedRxiv 2020. [CrossRef]

199. Abubakari, M. The Internet of Things (IoT) as an Emerging Technological Solution for the Covid-19 Pandemic Mitigation: An Overview. J. Phys. Conf. Ser. 2021, 1737, 012003. [CrossRef]

200. Ge, Y.; Zhang, X.; Han, B. Complex IoT control system modeling from perspectives of environment perception and information security. Mob. Netw. Appl. 2017, 22, 683-691. [CrossRef]

201. Kummitha, R.K.R. Smart technologies for fighting pandemics: The techno-and human-driven approaches in controlling the virus transmission. Gov. Inf. Q. 2020, 37, 101481. [CrossRef] [PubMed]

202. Nguyen, C.T.; Saputra, Y.M.; Van Huynh, N.; Nguyen, N.T.; Khoa, T.V.; Tuan, B.M.; Nguyen, D.N.; Hoang, D.T.; Vu, T.X.; Dutkiewicz, E.; et al. A comprehensive survey of enabling and emerging technologies for social distancing-Part I: Fundamentals and enabling technologies. IEEE Access 2020, 8, 153479-153507. [CrossRef]

203. Pflanzner, T.; Kertész, A. A survey of IoT cloud providers. In Proceedings of the 2016 39th International Convention on Information and Communication Technology, Electronics and Microelectronics (MIPRO), Opatija, Croatia, 30 May-3 June 2016; pp. 730-735.

204. Alauddin, S.; Bhuiyan, A.; Govindaiah, A.; Otero-Marquez, O.; Gildengorn, R.; Radell, J.E.; Ye, C.; Smith, R.T. A prospective trial of an artificial intelligence based telemedicine platform to stratify severity of age-related macular degeneration (AMD). Investig. Ophthalmol. Vis. Sci. 2020, 61, 1843.

205. Jang, S.M.; Hong, Y.J.; Lee, K.; Kim, S.; Chien, B.V.; Kim, J. Assessment of user needs for telemedicine robots in a developing nation hospital setting. Telemed. e-Health 2021, 27, 670-678. [CrossRef]

206. Gilgore, S. GWU Hospital Tackles COVID-19 with New Testing Site Telemedicine and Outreach on DC's East Side; The Department of Dermatology: Washington, DC, USA, 2020.

207. Shah, M.; Tosto, A. Industry voices-how rush University medical center's virtual investments became central to its COVID-19 response. FierceHealthcare, 13 April 2020, p. 1.

208. Berry, R.; Brawner, C.A.; Kipa, S.G.; Stevens, C.; Bloom, C.; Keteyian, S.J. Telemedicine home-based cardiac rehabilitation: A case series. J. Cardiopulm. Rehabil. Prev. 2020, 40, 245-248. [CrossRef] 
209. Liyanage-Don, N.A.; Schwartz, J.E.; Moise, N.; Bryant, K.B.; Bono, A.; Kronish, I.M. Abstract P156: Improvement In Blood Pressure Using Remote Patient Monitoring During COVID19. Hypertension 2020, 76, AP156. [CrossRef]

210. Chauhan, V.; Galwankar, S.; Arquilla, B.; Garg, M.; Di Somma, S.; El-Menyar, A.; Krishnan, V.; Gerber, J.; Holland, R.; Stawicki, S.P. Novel coronavirus (COVID-19): Leveraging telemedicine to optimize care while minimizing exposures and viral transmission. J. Emerg. Trauma Shock 2020, 13, 20.

211. Comstock, J. Israel's Sheba Hospital Turns to Telehealth to Treat Incoming Coronavirusexposed Patients. MobiHealthNews, 19 February 2020, p. 2.

212. Wittbold, K.A.; Carroll, C.; Iansiti, M.; Zhang, H.M.; Landman, A.B. How hospitals are using AI to battle COVID-19. Health and Behavioral Science, 3 April 2020, p. 1.

213. Kesavan, S.M.; Al Naimi, I.; Al Attar, F.; Rajinikanth, V.; Kadry, S. Res-UNet Supported Segmentation and Evaluation of COVID19 Lesion in Lung CT. In Proceedings of the 2021 International Conference on System, Computation, Automation and Networking (ICSCAN), Puducherry, India, 30-31 July 2021; pp. 1-4. [CrossRef]

214. Serte, S.; Serener, A. Discerning COVID-19 from mycoplasma and viral pneumonia on CT images via deep learning. In Proceedings of the 2020 4th International Symposium on Multidisciplinary Studies and Innovative Technologies (ISMSIT), Istanbul, Turkey, 22-24 October 2020; pp. 1-5. [CrossRef]

215. Benyelles, F.Z.; Sekkal, A.; Settouti, N. Content Based COVID-19 Chest X-Ray and CT Images Retrieval framework using Stacked Auto-Encoders. In Proceedings of the 2020 2nd International Workshop on Human-Centric Smart Environments for Health and Well-Being (IHSH), Boumerdes, Algeria, 9-10 February 2021; pp. 119-124. [CrossRef]

216. Rohmah, L.N.; Bustamam, A. Improved Classification of Coronavirus Disease (COVID-19) based on Combination of Texture Features using CT Scan and X-ray Images. In Proceedings of the 2020 3rd International Conference on Information and Communications Technology (ICOIACT), Yogyakarta, Indonesia, 24-25 November 2020; pp. 105-109. [CrossRef]

217. Meng, L.; Dong, D.; Li, L.; Niu, M.; Bai, Y.; Wang, M.; Qiu, X.; Zha, Y.; Tian, J. A Deep Learning Prognosis Model Help Alert for COVID-19 Patients at High-Risk of Death: A Multi-Center Study. IEEE J. Biomed. Health Inform. 2020, 24, 3576-3584. [CrossRef]

218. Nazir, M.; Jan, Z.; Sajjad, M. Facial expression recognition using histogram of oriented gradients based transformed features. Clust. Comput. 2018, 21, 539-548. [CrossRef]

219. He, K.; Zhang, X.; Ren, S.; Sun, J. Deep residual learning for image recognition. In Proceedings of the IEEE Conference on Computer Vision and Pattern Recognition, Las Vegas, NV, USA, 27-30 June 2016; pp. 770-778.

220. Bérubé, C.; Theresa, S.; Roman, K.; Elgar, F.; Florian, W.; Filipe, B.; Tobias, K. Voice-Based Conversational Agents for the Prevention and Management of Chronic and Mental Health Conditions: Systematic Literature Review. J. Med. Internet Res. 2021, 23, e25933. [CrossRef] [PubMed]

221. Alafif, T.; Tehame, A.M.; Bajaba, S.; Barnawi, A.; Zia, S. Machine and deep learning towards COVID-19 diagnosis and treatment: Survey, challenges, and future directions. Int. J. Environ. Res. Public Health 2021, 18, 1117. [CrossRef] [PubMed]

222. World Health Organization. WHO Coronavirus Disease (COVID-19) Dashboard. 2021. Available online: https:/ / covid19.who. int/ (accessed on 13 October 2021).

223. Abd-Alrazaq, A.A.; Alajlani, M.; Alhuwail, D.; Erbad, A.; Giannicchi, A.; Shah, Z.; Hamdi, M.; Househ, M. Blockchain technologies to mitigate COVID-19 challenges: A scoping review. Comput. Methods Programs Biomed. Update 2020, 1, 100001. [CrossRef] [PubMed]

224. Kalla, A.; Hewa, T.; Mishra, R.A.; Ylianttila, M.; Liyanage, M. The Role of Blockchain to Fight Against COVID-19. IEEE Eng. Manag. Rev. 2020, 48, 85-96. [CrossRef]

225. Singh, G.; Levi, J. MiPasa Project and IBM Blockchain Team on Open Data Platform to Support COVID-19 Response; IBM: Armonk, NY, USA, 2020; Volume 27.

226. Azbeg, K.; Ouchetto, O.; Andaloussi, S.; Fetjah, L. A Taxonomic Review of the Use of IoT and Blockchain in Healthcare Applications. IRBM 2021, in press. [CrossRef]

227. Sengupta, J.; Ruj, S.; Bit, S.D. A comprehensive survey on attacks, security issues and blockchain solutions for IoT and IIoT. J. Netw. Comput. Appl. 2020, 149, 102481. [CrossRef]

228. Kumar, R.; Tripathi, R. A Secure and Distributed Framework for sharing COVID-19 patient Reports using Consortium Blockchain and IPFS. In Proceedings of the 2020 Sixth International Conference on Parallel, Distributed and Grid Computing (PDGC), Waknaghat, India, 6-8 November 2020; pp. 231-236. [CrossRef]

229. Deka, S.K.; Goswami, S.; Anand, A. A Blockchain Based Technique for Storing Vaccination Records. In Proceedings of the 2020 IEEE Bombay Section Signature Conference (IBSSC), Mumbai, India, 4-6 December 2020; pp. 135-139. [CrossRef]

230. Paavolainen, S.; Carr, C. Security Properties of Light Clients on the Ethereum Blockchain. IEEE Access 2020, 8, 124339-124358. [CrossRef]

231. Dai, H.N.; Imran, M.; Haider, N. Blockchain-Enabled Internet of Medical Things to Combat COVID-19. IEEE Internet Things Mag. 2020, 3, 52-57. [CrossRef]

232. Maccari, L.; Cagno, V. Do we need a contact tracing app? Comput. Commun. 2021, 166, 9-18. [CrossRef]

233. Gupta, R.; Kumari, A.; Tanwar, S.; Kumar, N. Blockchain-Envisioned Softwarized Multi-Swarming UAVs to Tackle COVID-I9 Situations. IEEE Netw. 2021, 35, 160-167. [CrossRef]

234. Vaishya, R.; Javaid, M.; Khan, I.H.; Haleem, A. Artificial Intelligence (AI) applications for COVID-19 pandemic. Diabetes Metab. Syndr. Clin. Res. Rev. 2020, 14, 337-339. [CrossRef] [PubMed] 
235. Cirillo, F.; Gómez, D.; Diez, L.; Elicegui Maestro, I.; Gilbert, T.B.J.; Akhavan, R. Smart City IoT Services Creation Through Large-Scale Collaboration. IEEE Internet Things J. 2020, 7, 5267-5275. [CrossRef]

236. Sun, S.; Du, R.; Chen, S.; Li, W. Blockchain-Based IoT Access Control System: Towards Security, Lightweight, and Cross-Domain. IEEE Access 2021, 9, 36868-36878. [CrossRef]

237. Khan, P.W.; Byun, Y.C. Blockchain-Based Peer-to-Peer Energy Trading and Charging Payment System for Electric Vehicles. Sustainability 2021, 13, 7962. [CrossRef]

238. Oktian, Y.E.; Lee, S.G. BorderChain: Blockchain-Based Access Control Framework for the Internet of Things Endpoint. IEEE Access 2021, 9, 3592-3615. [CrossRef]

239. Lockl, J.; Schlatt, V.; Schweizer, A.; Urbach, N.; Harth, N. Toward Trust in Internet of Things Ecosystems: Design Principles for Blockchain-Based IoT Applications. IEEE Trans. Eng. Manag. 2020, 67, 1256-1270. [CrossRef]

240. Shahbazi, Z.; Byun, Y.C.; Kwak, H.Y. Smart Home Gateway Based on Integration of Deep Reinforcement Learning and Blockchain Framework. Processes 2021, 9, 1593. [CrossRef]

241. Goyal, S.; Sharma, S.K.; Bhatia, P.K. Blockchain for the Security and Privacy of IoT-Based Smart Homes. In Blockchain Technology for Data Privacy Management; CRC Press: Boca Raton, FL, USA, 2021; pp. 239-252.

242. Shahbazi, Z.; Byun, Y.C. Improving Transactional Data System Based on an Edge Computing-Blockchain-Machine Learning Integrated Framework. Processes 2021, 9, 92. [CrossRef]

243. Zhang, L.; Zou, Y.; Wang, W.; Jin, Z.; Su, Y.; Chen, H. Resource allocation and trust computing for blockchain-enabled edge computing system. Comput. Secur. 2021, 105, 102249. [CrossRef]

244. Shahbazi, Z.; Byun, Y.C. A Procedure for Tracing Supply Chains for Perishable Food Based on Blockchain, Machine Learning and Fuzzy Logic. Electronics 2021, 10, 41. [CrossRef]

245. Saha, R.; Biswas, S.; Sarma, S.; Karmakar, S.; Das, P. Design and Implementation of Routing Algorithm to Enhance Network Lifetime in WBAN. Wirel. Pers. Commun. 2021, 118, 961-998. [CrossRef]

246. Holmgren, A.J.; Apathy, N.C.; Adler-Milstein, J. Barriers to hospital electronic public health reporting and implications for the COVID-19 pandemic. J. Am. Med. Inform. Assoc. 2020, 27, 1306-1309. [CrossRef]

247. Nguyen, T.; Raich, R. Active Learning in Incomplete Label Multiple Instance Multiple Label Learning. arXiv 2021, arXiv:2107.10804.

248. Young, B.C.; Eyre, D.W.; Kendrick, S.; White, C.; Smith, S.; Beveridge, G.; Nonnenmacher, T.; Ichofu, F.; Hillier, J.; Oakley, S.; et al. Daily testing for contacts of individuals with SARS-CoV-2 infection and attendance and SARS-CoV-2 transmission in English secondary schools and colleges: An open-label, cluster-randomised trial. Lancet 2021. [CrossRef]

249. Awasthi, P.; Beutel, A.; Kleindessner, M.; Morgenstern, J.; Wang, X. Evaluating Fairness of Machine Learning Models Under Uncertain and Incomplete Information. In Proceedings of the 2021 ACM Conference on Fairness, Accountability, and Transparency, Toronto, ON, Canada, 3-10 March 2021; pp. 206-214.

250. Biswas, S.; Sharif, K.; Li, F.; Nour, B.; Wang, Y. A Scalable Blockchain Framework for Secure Transactions in IoT. IEEE Internet Things J. 2019, 6, 4650-4659. [CrossRef]

251. Khanouche, M.E.; Atmani, N.; Cherifi, A. Improved Teaching Learning-Based QoS-Aware Services Composition for Internet of Things. IEEE Syst. J. 2020, 14, 4155-4164. [CrossRef]

252. Atlam, H.F.; Alenezi, A.; Alassafi, M.O.; Wills, G. Blockchain with internet of things: Benefits, challenges, and future directions Int. J. Intell. Syst. Appl. 2018, 10, 40-48. [CrossRef]

253. Chahal, R.K.; Kumar, N.; Batra, S. Trust management in social Internet of Things: A taxonomy, open issues, and challenges. Comput. Commun. 2020, 150, 13-46. [CrossRef]

254. Zhaofeng, M.; Lingyun, W.; Xiaochang, W.; Zhen, W.; Weizhe, Z. Blockchain-Enabled Decentralized Trust Management and Secure Usage Control of IoT Big Data. IEEE Internet Things J. 2020, 7, 4000-4015. [CrossRef]

255. Mollah, M.B.; Zhao, J.; Niyato, D.; Guan, Y.L.; Yuen, C.; Sun, S.; Lam, K.Y.; Koh, L.H. Blockchain for the Internet of Vehicles Towards Intelligent Transportation Systems: A Survey. IEEE Internet Things J. 2021, 8, 4157-4185. [CrossRef]

256. Li, X.; Mei, Y.; Gong, J.; Xiang, F.; Sun, Z. A Blockchain Privacy Protection Scheme Based on Ring Signature. IEEE Access 2020, 8, 76765-76772. [CrossRef]

257. Zhang, C.; Zhu, L.; Xu, C.; Zhang, C.; Sharif, K.; Wu, H.; Westermann, H. BSFP: Blockchain-Enabled Smart Parking With Fairness, Reliability and Privacy Protection. IEEE Trans. Veh. Technol. 2020, 69, 6578-6591. [CrossRef]

258. Queralta, J.P.; Qingqing, L.; Zou, Z.; Westerlund, T. Enhancing Autonomy with Blockchain and Multi-Access Edge Computing in Distributed Robotic Systems. In Proceedings of the 2020 Fifth International Conference on Fog and Mobile Edge Computing (FMEC), Paris, France, 20-23 April 2020; pp. 180-187. [CrossRef]

259. Uddin, M.A.; Stranieri, A.; Gondal, I.; Balasubramanian, V. Blockchain leveraged decentralized IoT eHealth framework. Internet Things 2020, 9, 100159. [CrossRef]

260. Uddin, M.A.; Stranieri, A.; Gondal, I.; Balasubramanian, V. Continuous patient monitoring with a patient centric agent: A block architecture. IEEE Access 2018, 6, 32700-32726. [CrossRef]

261. Yu, G.; Wang, X.; Yu, K.; Ni, W.; Zhang, J.A.; Liu, R.P. Survey: Sharding in Blockchains. IEEE Access 2020, 8, $14155-14181$. [CrossRef] 
262. Ashraf Uddin, M.; Stranieri, A.; Gondal, I.; Balasubramanian, V. Dynamically Recommending Repositories for Health Data: A Machine Learning Model. In Proceedings of the Australasian Computer Science Week Multiconference, Melbourne, VIC, Australia, 3-7 February 2020; pp. 1-10.

263. Cullen, A.; Ferraro, P.; King, C.; Shorten, R. On the Resilience of DAG-Based Distributed Ledgers in IoT Applications. IEEE Internet Things J. 2020, 7, 7112-7122. [CrossRef] 